\title{
Glycerolipidome responses to freezing- and chilling-induced injuries: examples in Arabidopsis and rice
}

\author{
Guowei Zheng ${ }^{1,2+}$, Lixia $\mathrm{Li}^{3+}$ and Weiqi $\mathrm{Li}^{1,2^{*}}$
}

\begin{abstract}
Background: Glycerolipids are the principal constituent of cellular membranes; remodelling of glycerolipids plays important roles in temperature adaptation in plants. Temperate plants can endure freezing stress, but even chilling at above-zero temperatures can induce death in tropical species. However, little is known about the differences in glycerolipid response to low temperatures between chilling-sensitive and freezing-tolerant plants. Using ESI-MS/ MS-based lipidomic analysis, we compared the glycerolipidome of chilling $\left(4\right.$ and $10{ }^{\circ} \mathrm{C}$ )-treated rice with that of freezing $\left(-6\right.$ and $\left.-12{ }^{\circ} \mathrm{C}\right)$-treated Arabidopsis, both immediately after these low-temperature treatments and after a subsequent recovery culture period.

Results: Arabidopsis is a 16:3 plant that harbours both eukaryotic and prokaryotic-type lipid synthesis pathways, while rice is an 18:3 plant that harbours only the eukaryotic lipid synthesis pathway. Arabidopsis contains higher levels of galactolipids than rice and has a higher double bond index (DBI). Arabidopsis contains lower levels of high melting point phosphatidylglycerol (PG) molecules and has a lower average acyl chain length (ACL). Marked phospholipid degradation occurred during the recovery culture period of non-lethal chilling treated rice, but did not occur in non-lethal freezing treated Arabidopsis. Glycerolipids with larger head groups were synthesized more in Arabidopsis than in rice at sub-lethal low-temperatures. Levels of phosphatidic acid (PA) and phosphatidylinositol (PI) rose in both plants after low-temperature treatment. The DBI and ACL of total lipids did not change during low-temperature treatment.

Conclusions: A higher DBI and a lower ACL could make the membranes of Arabidopsis more fluid at low temperatures. The ability to synthesize glycerolipids containing a larger head group may correlate with lowtemperature tolerance. The low-temperature-induced increase of PA may play a dual role in plant responses to low temperatures: as a lipid signal that initiates tolerance responses, and as a structural molecule that, on extensive in large accumulation, could damage the integrity of membranes. Changes in $A C L$ and $D B I$ are responses of plants to long-term low temperature.
\end{abstract}

Keywords: Chilling, Freezing, Arabidopsis, Rice, Glycerolipidome

\footnotetext{
* Correspondence: weiqili@mail.kib.ac.cn

${ }^{\dagger}$ Equal contributors

${ }^{1}$ Key Laboratory for Plant Diversity and Biogeography of East Asia, Kunming

Institute of Botany, Chinese Academy of Sciences, Kunming, Yunnan 650202,

People's Republic of China

${ }^{2}$ Germplasm Bank of Wild Species, Kunming Institute of Botany, Chinese

Academy of Sciences, Kunming 650201, People's Republic of China

Full list of author information is available at the end of the article
} 


\section{Background}

Low-temperature injury is one of the most important factors causing substantial agricultural losses. The ability of plants to tolerate low temperatures is an important determinant of their productivity and geographical distribution. The climate of the area from which a plant originates has a major influence on its sensitivity to freezing and chilling stresses [1]. Many temperate plants can tolerate sub-zero temperatures (freezing), and, after exposure to low temperatures (usually $4{ }^{\circ} \mathrm{C}$ ) for a period, they develop increased freezing tolerance [2]. However, in some plants from tropical or subtropical areas, such as rice, exposure even to low temperatures above $0{ }^{\circ} \mathrm{C}$ (chilling) can induce severe damage [3]. Freezing-induced injury to plants differs from that associated with chilling, because of the presence of ice inside plant tissues. As a result, there are major differences in the physiological, biochemical and molecular responses of plants to freezing and chilling stresses [4-7]. For example, chilling tolerance in pea (Pisum sativum) was suggested to be related to an increase in proteins that are involved in osmotic adjustment and antioxidative responses; however, freezing tolerance seemed to depend on proteins that maintain the stability of the photosystems as well as the capacity for photosynthesis [5].

Membranes are integral to the structure and function of all cells and are very sensitive to environmental changes. The responses of membranes to temperature changes have been investigated extensively and results indicate that membrane damage is the major cause of low-temperature-induced injury in plants [8-10]. Phospholipids and galactolipids are the main glycerolipids, and are respectively the major constituents of plasma and chloroplast membranes. Regulation of the level of saturation and the constitution of glycerolipids is important for plants to maintain the integrity and fluidity of their membranes under temperature stresses [11-13]. After introduction into a warmer lowland area from an alpine region, the level of saturation in all measured phospholipids of Meconopsis racemosa leaves increased [14]. Changing the level of saturation of glycerolipids has been identified as a strategy used by plants to cope with both long-term high and low temperatures; in contrast, upon short-term temperature stresses, the level of saturation of glycerolipids was maintained [15]. In addition to reducing the level of saturation of glycerolipids, adjustment of the composition of lipids to balance the ratio of bilayer- to non-bilayer-forming membrane is also important for plant responses to low temperatures. At low temperatures, the proportion of phospholipids tends to increase [13, 16]. Glycerolipids harbouring large polar head groups, such as digalactosyldiacylglycerol (DGDG) and phosphatidylcholine (PC), are bilayer lipids that may increase membrane stability.
In contrast, monogalactosyldiacylglycerol (MGDG) and phosphatidylethanolamine (PE), which have relatively small head groups, show a higher propensity for transition to non-bilayer $\mathrm{H}_{\mathrm{II}}$-type structures $[17,18]$. Increases in the ratio of bilayer- to non-bilayer-forming membrane lipids, for example PC:PE and DGDG:MGDG, have been observed in plants responding to low temperatures $[18,19]$. Leaves of Brassica napus showed a tendency to synthesise more desaturated PC and MGDG at low temperatures [20]. Plants that have different kinds of MGDG molecules have different pathways for synthesizing lipids: plants that have only 36:6 (total acyl carbons:total double bonds) MGDG molecules are 18:3 plants, which only have the eukaryotictype lipid synthesis pathway; plants that contain both 34:6 and 36:6 MGDG molecules are 16:3 plants, which have both prokaryotic and eukaryotic-type lipid synthesis pathways [21]. However, little is known about the relationships between the different pathways for synthesizing lipids in plants that are tolerant to low temperatures.

Most studies on changes in the lipidome in response to low temperatures used the model plant Arabidopsis, and investigated its freezing tolerance [12, 13, 18, 22]. However, freezing-induced membrane damage may differ from that associated with chilling, because cells can suffer different types of injury. The lipidome responses of plants upon chilling-induced injury or even death have scarcely been studied; to the best of our knowledge, only Li et al. have focused on this issue, studying the Jatropha curcas lipidome response to chilling treatment [23].

Rice is a chilling-sensitive plant that dies after the temperature falls to $4{ }^{\circ} \mathrm{C}$ [3]. In contrast, after acclimation to cold at $4{ }^{\circ} \mathrm{C}$, Arabidopsis can tolerate freezing temperatures as low as $-6{ }^{\circ} \mathrm{C}$ [24]. We are interested in the responses of the lipidomes of plants that have different levels of tolerance to low temperatures in terms of chilling- and freezing-induced injury. Here, we report an investigation of the responses of the glycerolipidomes of rice and Arabidopsis after exposure of the plants to chilling $\left(4\right.$ and $\left.10{ }^{\circ} \mathrm{C}\right)$ and freezing $(-6$ and $-12{ }^{\circ} \mathrm{C}$ ) temperatures, respectively. Our principal aims were to address two main questions: (i) do different lipidome profiles contribute to the different capacities of Arabidopsis and rice to tolerate low temperatures? (ii) what are the differences in lipidome response between Arabidopsis and rice during treatment at different low temperatures?

\section{Results}

We used an ESI-MS/MS-based lipid profiling approach [25] to investigate changes in Arabidopsis and rice leaf lipid profiles during low-temperature treatments at above and below $0{ }^{\circ} \mathrm{C}$. This lipidomic approach allowed us to profile 11 lipid classes, which contained 150 molecular species of membrane glycerolipids, including two classes 
of galactolipids, six of phospholipids and three of lysophospholipids (lysoPLs). For sub-zero low-temperature (freezing) treatment, cold-acclimated $\left(4^{\circ} \mathrm{C}\right.$ for 3 days) Arabidopsis was treated at non-lethal $\left(-6^{\circ} \mathrm{C}\right)$ and lethal $\left(-12{ }^{\circ} \mathrm{C}\right)$ sub-zero temperatures. For low-temperature treatment above $0{ }^{\circ} \mathrm{C}$ (chilling), rice seedlings were treated at 10 or $4{ }^{\circ} \mathrm{C}$ for 6 days, which represented nonlethal and lethal treatments, respectively. For Arabidopsis and rice respectively, plants treated at -6 and $10{ }^{\circ} \mathrm{C}$ would survive after 3 days of recovery from lowtemperature treatment, whereas plants treated at -12 and $4{ }^{\circ} \mathrm{C}$ would die after this period. Leaf lipid profiles were analysed immediately after low-temperature treatment and after subsequent recovery culture for 1 and
3 days. Five independent biological replicates were analysed for each treatment.

\section{Different lipid profiles between cold-acclimated Arabidopsis and rice}

In the first analysis, we compared the lipid profile of coldacclimated Arabidopsis with that of rice grown in normal conditions $\left(22 / 18^{\circ} \mathrm{C}\right.$, day/night). Galactolipids and phospholipids are the main components of the glycerolipids in plants. Among the glycerolipids that we tested, the level of galactolipids was higher in Arabidopsis than in rice; the ratio of galactolipids to phospholipids was 8.83 and 6.46 in Arabidopsis and rice respectively (Table 1). MGDG and DGDG are the main extraplastidic lipids, while PC and PE

Table 1 Total amount of lipid in each head-group class and ratios of different lipid classes after various low-temperature treatments of Arabidopsis and rice

\begin{tabular}{|c|c|c|c|c|c|c|c|c|}
\hline \multirow[t]{2}{*}{ Lipid class } & \multirow{2}{*}{$\begin{array}{l}\text { Plant } \\
\text { species }\end{array}$} & \multirow[b]{2}{*}{ C } & \multicolumn{3}{|c|}{ Arabidopsis $\left(-6^{\circ} \mathrm{C}\right) /$ rice $\left(10^{\circ} \mathrm{C}\right)$} & \multicolumn{3}{|c|}{ Arabidopsis $\left(-12^{\circ} \mathrm{C}\right) /$ rice $\left(4^{\circ} \mathrm{C}\right)$} \\
\hline & & & $\bar{T}$ & R1 & R3 & $\overline{\mathrm{T}}$ & R1 & R3 \\
\hline & & \multicolumn{7}{|c|}{ Lipid content (nmol per mg dry weight) } \\
\hline \multirow[t]{2}{*}{ DGDG } & Arabidopsis & $47.49 \pm 3.00^{\mathrm{ab}}$ & $50.54 \pm 4.68^{\mathrm{a}}$ & $41.28 \pm 3.71^{c}$ & $45.22 \pm 7.03^{\mathrm{bc}}$ & $17.17 \pm 2.12^{d}$ & $5.88 \pm 1.01^{\mathrm{e}}$ & $3.41 \pm 1.25^{\mathrm{e}}$ \\
\hline & Rice & $38.69 \pm 2.29^{\mathrm{ab}}$ & $39.07 \pm 3.08^{\mathrm{ab}}$ & $38.22 \pm 2.19^{b}$ & $41.58 \pm 1.12^{\mathrm{a}}$ & $27.91 \pm 3.46^{c}$ & $22.61 \pm 1.70^{d}$ & $8.43 \pm 1.12^{\mathrm{e}}$ \\
\hline \multirow[t]{2}{*}{ MGDG } & Arabidopsis & $235.54 \pm 17.77^{a}$ & $159.59 \pm 26.35^{b}$ & $174.79 \pm 24.64^{b}$ & $213.70 \pm 24.43^{\mathrm{a}}$ & $7.68 \pm 1.02^{c}$ & $3.93 \pm 0.65^{c}$ & $2.82 \pm 0.62^{c}$ \\
\hline & Rice & $103.43 \pm 5.93^{\mathrm{a}}$ & $73.53 \pm 4.96^{c}$ & $70.97 \pm 3.83^{c}$ & $93.72 \pm 4.07^{b}$ & $51.03 \pm 11.24^{d}$ & $22.28 \pm 2.44^{e}$ & $6.47 \pm 2.54^{f}$ \\
\hline \multirow[t]{2}{*}{ PG } & Arabidopsis & $11.12 \pm 3.13^{\mathrm{ab}}$ & $11.77 \pm 1.87^{\mathrm{a}}$ & $9.56 \pm 1.01^{b}$ & $9.68 \pm 1.32^{b}$ & $4.97 \pm 0.75^{c}$ & $2.36 \pm 0.42^{d}$ & $1.42 \pm 0.17^{d}$ \\
\hline & Rice & $5.46 \pm 0.88^{\mathrm{a}}$ & $3.05 \pm 0.28^{b}$ & $2.72 \pm 0.25^{b c}$ & $2.99 \pm 0.38^{b c}$ & $2.47 \pm 0.43^{c}$ & $1.45 \pm 0.16^{d}$ & $0.54 \pm 0.09^{e}$ \\
\hline \multirow[t]{2}{*}{ PA } & Arabidopsis & $0.25 \pm 0.07^{d}$ & $2.32 \pm 0.83^{c d}$ & $1.41 \pm 0.69^{d}$ & $0.50 \pm 0.10^{d}$ & $24.75 \pm 4.13^{\mathrm{a}}$ & $20.74 \pm 5.88^{b}$ & $6.00 \pm 3.24^{c}$ \\
\hline & Rice & $0.18 \pm 0.07^{c}$ & $0.47 \pm 0.09^{c}$ & $0.11 \pm 0.02^{c}$ & $0.12 \pm 0.03^{c}$ & $3.57 \pm 1.23^{b}$ & $5.90 \pm 1.26^{\mathrm{a}}$ & $2.81 \pm 0.27^{b}$ \\
\hline \multirow[t]{2}{*}{$P C$} & Arabidopsis & $13.80 \pm 1.34^{\mathrm{b}}$ & $13.52 \pm 2.35^{b}$ & $16.51 \pm 1.79^{\mathrm{a}}$ & $15.94 \pm 1.07^{\mathrm{a}}$ & $3.18 \pm 0.86^{c}$ & $0.68 \pm 0.52^{d}$ & $0.76 \pm 0.43^{d}$ \\
\hline & Rice & $12.66 \pm 0.94^{a}$ & $10.63 \pm 0.72^{b}$ & $9.77 \pm 0.37^{\mathrm{bc}}$ & $9.13 \pm 0.73^{c}$ & $9.84 \pm 1.22^{\mathrm{bc}}$ & $6.30 \pm 0.37^{d}$ & $2.57 \pm 0.59^{e}$ \\
\hline \multirow[t]{2}{*}{ PE } & Arabidopsis & $2.18 \pm 0.39^{a}$ & $2.15 \pm 0.81^{a}$ & $2.66 \pm 0.99^{a}$ & $2.50 \pm 0.76^{a}$ & $0.36 \pm 0.16^{b}$ & $0.09 \pm 0.07^{b}$ & $0.07 \pm 0.05^{b}$ \\
\hline & Rice & $0.97 \pm 0.21^{b}$ & $1.41 \pm 0.17^{\mathrm{a}}$ & $1.03 \pm 0.15^{b}$ & $0.76 \pm 0.12^{c}$ & $1.11 \pm 0.15^{b}$ & $0.70 \pm 0.05^{c}$ & $0.25 \pm 0.08^{d}$ \\
\hline \multirow[t]{2}{*}{$\mathrm{Pl}$} & Arabidopsis & $5.21 \pm 0.65^{b}$ & $6.93 \pm 1.59^{\mathrm{a}}$ & $6.90 \pm 1.35^{\mathrm{a}}$ & $6.92 \pm 0.56^{a}$ & $5.68 \pm 0.59^{b}$ & $3.31 \pm 0.31^{c}$ & $1.06 \pm 0.24^{d}$ \\
\hline & Rice & $2.61 \pm 0.22^{\mathrm{ab}}$ & $2.46 \pm 0.19^{b}$ & $2.47 \pm 0.24^{b}$ & $2.48 \pm 0.26^{b}$ & $1.72 \pm 0.05^{c}$ & $2.84 \pm 0.23^{\mathrm{a}}$ & $1.56 \pm 0.32^{c}$ \\
\hline \multirow[t]{2}{*}{ PS } & Arabidopsis & $0.21 \pm 0.06^{\mathrm{ab}}$ & $0.09 \pm 0.03^{c}$ & $0.18 \pm 0.04^{b}$ & $0.25 \pm 0.04^{\mathrm{a}}$ & $0.03 \pm 0.01^{d}$ & $0.02 \pm 0.01^{d}$ & $0.03 \pm 0.03^{d}$ \\
\hline & Rice & $0.22 \pm 0.03^{a}$ & $0.15 \pm 0.03^{b c}$ & $0.11 \pm 0.01^{\mathrm{de}}$ & $0.13 \pm 0.02^{c d}$ & $0.17 \pm 0.03^{b}$ & $0.14 \pm 0.01^{c d}$ & $0.07 \pm 0.03^{e}$ \\
\hline \multirow[t]{3}{*}{ Total } & Arabidopsis & $315.92 \pm 16.69^{a}$ & $247.16 \pm 27.43^{b}$ & $253.44 \pm 29.78^{b}$ & $294.83 \pm 33.53^{\mathrm{a}}$ & $64.20 \pm 5.07^{c}$ & $37.37 \pm 6.16^{\mathrm{cd}}$ & $15.83 \pm 3.84^{d}$ \\
\hline & Rice & $164.27 \pm 7.38^{\mathrm{a}}$ & $130.88 \pm 8.70^{c}$ & $125.46 \pm 6.23^{c}$ & $149.96 \pm 5.93^{b}$ & $98.00 \pm 15.14^{d}$ & $62.43 \pm 3.88^{e}$ & $22.82 \pm 3.74^{f}$ \\
\hline & & Ratio of lipid & & & & & & \\
\hline \multirow[t]{2}{*}{ MGDG:DGDG } & Arabidopsis & $4.97 \pm 0.48^{\mathrm{a} *}$ & $3.20 \pm 0.71^{c *}$ & $4.23 \pm 0.46^{b *}$ & $4.75 \pm 0.31^{\mathrm{ab} *}$ & $0.46 \pm 0.09^{d *}$ & $0.67 \pm 0.07^{d *}$ & $0.91 \pm 0.37^{d}$ \\
\hline & Rice & $2.67 \pm 0.10^{a}$ & $1.88 \pm 0.08^{c}$ & $1.86 \pm 0.06^{c}$ & $2.23 \pm 0.08^{b}$ & $1.81 \pm 0.20^{c}$ & $0.99 \pm 0.10^{d}$ & $0.75 \pm 0.23^{e}$ \\
\hline \multirow[t]{2}{*}{ PC:PE } & Arabidopsis & $6.47 \pm 1.09^{c *}$ & $6.93 \pm 2.33^{c}$ & $5.46 \pm 0.94^{\mathrm{c} *}$ & $6.89 \pm 2.10^{c *}$ & $8.31 \pm 0.91^{b}$ & $9.30 \pm 4.93^{\mathrm{a}}$ & $13.48 \pm 4.07^{\mathrm{a}}$ \\
\hline & Rice & $14.09 \pm 0.57^{a}$ & $7.57 \pm 0.74^{e}$ & $9.53 \pm 1.02^{\mathrm{cd}}$ & $12.20 \pm 1.46^{b}$ & $8.92 \pm 0.29^{\mathrm{de}}$ & $9.10 \pm 0.88^{d}$ & $10.67 \pm 1.03^{c}$ \\
\hline \multirow[t]{2}{*}{ Galactolipid:Phospholipid } & Arabidopsis & $8.83 \pm 1.64^{\mathrm{a} *}$ & $5.79 \pm 0.87^{c}$ & $5.81 \pm 0.55^{c *}$ & $7.23 \pm 0.52^{\mathrm{b*}}$ & $0.65 \pm 0.10^{\mathrm{d} *}$ & $0.38 \pm 0.12^{\mathrm{d} *}$ & $0.78 \pm 0.39^{d *}$ \\
\hline & Rice & $6.46 \pm 0.60^{b}$ & $6.19 \pm 0.24^{b}$ & $6.75 \pm 0.38^{b}$ & $8.63 \pm 0.44^{a}$ & $4.17 \pm 0.67^{c}$ & $2.61 \pm 0.33^{d}$ & $1.96 \pm 0.61^{\mathrm{e}}$ \\
\hline
\end{tabular}

" $\mathrm{C}$ " represents "control", " $\mathrm{T}$ " indicates samples taken immediately after each cold treatment, and "R1" and "R3" indicate samples taken after post treatment recovery culture for 1 and 3 days, respectively. Values in the same row marked with different letters are significantly different, while an asterisk means that the value in Arabidopsis is significantly different from that in rice $(p<0.05)$. Values are means \pm S.D. $(n=4$ or 5$)$ 
are the main plastidic lipids. These lipid classes have differently sized head groups and play different roles in the integrity of membranes under stresses. The ratio of MGDG/DGDG in cold-acclimated Arabidopsis was 4.97, whereas in normal growth rice it was 2.67. The ratio of $\mathrm{PC} / \mathrm{PE}$ in Arabidopsis was 6.47, whereas in rice it was 14.09 (Table 1).

From detailed comparative analysis of the lipids between the two plants, we found that Arabidopsis contained both 34:6 and 36:6 MGDG. However, rice contained only 36:6 MGDG molecules (Fig. 1; Additional file 1: Table S1). This difference shows that the two plants have different lipid synthesis pathways; Arabidopsis is a 16:3 plant that has both eukaryotic and prokaryotic-type lipid synthesis pathways, while rice is an 18:3 plant that has only the eukaryotic-type lipid synthesis pathway [21]. Some of the PG molecules with compositions of 16:0/16:0 and 16:0/16:1, such as 32:0 and 32:1 PG, respectively, have high melting points. The levels of these PG molecules correlate positively with the cold sensitivity of plants $[26,27]$. The content of 32:0 PG in rice was found to be almost double that in Arabidopsis. In addition, the content of 32:1 PG was eight times greater in rice than in Arabidopsis (Fig. 1).

The ACL and DBI of glycerolipids are two determinants of membrane fluidity. To understand membrane fluidity under low-temperature stresses, we compared the ACL and DBI between Arabidopsis and rice. Fatty acids with more than 18 carbon atoms per chain are known as very long chain fatty acids (VLCFAs) [28]. Glycerolipids that have acyl chains with more than 36 carbons, such as MGDG, DGDG, PC, PE and PS, contain

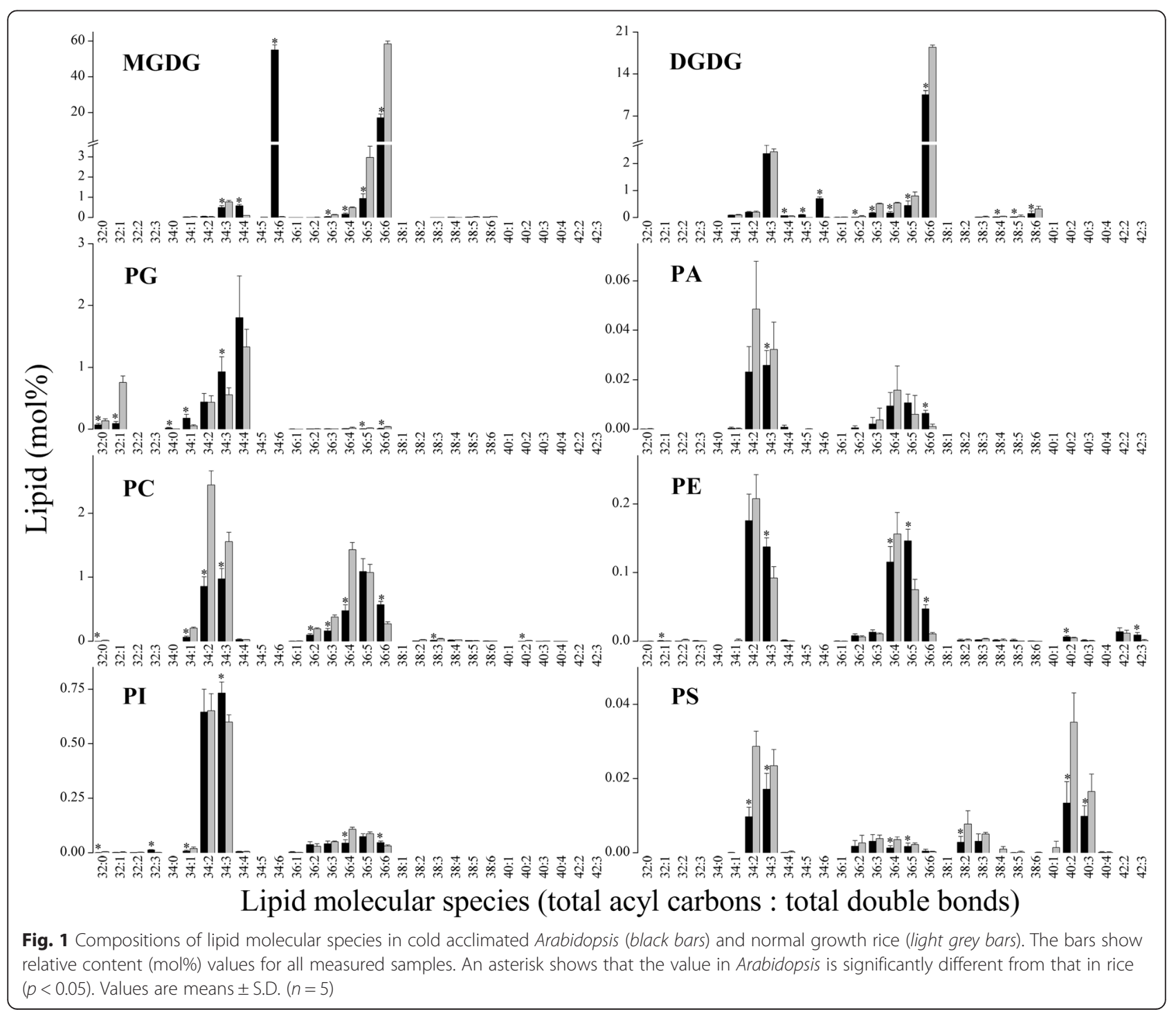


VLCFAs (Fig. 1). The relative content of galactolipids with an acyl chain that has $>36$ carbons was found to be $0.198 \%$ and $0.401 \%$ in Arabidopsis and rice, respectively, while for phospholipids the corresponding values were $0.125 \%$ and $0.205 \%$, respectively. By calculating the acyl chain length of eight kinds of glycerolipid, we found that the ACL of total lipids was 34.66 in cold-acclimated Arabidopsis and 35.73 in normal growth rice (Table 2). The fact that the ACL of galactolipids is lower in Arabidopsis than in rice may contribute to the lower ACL of total lipids in Arabidopsis, because galactolipids constitute $>80 \%$ of the total lipids. In addition, the ACL of MGDG in Arabidopsis was 1.48 carbons less than that in rice. However, the ACL of most phospholipids, except for PS, in Arabidopsis was greater than that in rice (Table 2). The DBI is the average number of double bonds in the fatty acid chains of a glycerolipid molecular species; a high DBI indicates the presence of more highly unsaturated membrane lipids, and vice versa. For all glycerolipid classes, the DBI of Arabidopsis differs from that of rice (except for PI, which did not show any difference between the two plants). The levels of the DBI of most lipid classes, including total lipids, except for DGDG, were higher in Arabidopsis than in rice (Table 3).

\section{Changes in membrane lipid content distinguished lethal} from sub-lethal low-temperature treated plants

The effects of different low-temperature treatments on the glycerolipidome and their relationships were clarified using principal component analysis (PCA). In the PCA analysis of absolute levels of glycerolipids, the two principal components explained $71 \%$ and $17 \%$ of the overall variance (Fig. 2a). The loadings of PC1 identified MGDG, DGDG, PC and PE as being most important for the separation, whereas for PC2, phosphatidic acid (PA) and PI were identified (Additional file 1: Table S2). The PCA separated Arabidopsis and rice efficiently; it also separated lethal and sub-lethal low-temperature treated plants (Fig. 2a). Loadings of PC1 represented the most abundant glycerolipids in plants; the separation of different samples along this axis may indicate low-temperature induced lipid degradation. PC2 represented the two signalling lipids, PA and PI. Along this axis, Arabidopsis and rice were separated, which may indicate that different lipid signals occur during low-temperature treatment of these two plants. To compare the compositional variability and inter-conversion of membrane lipids, we performed a PCA separately for the relative levels of the eight classes of lipid (mol\%) (Fig. 2b). The results of the PCA of lipid

Table 2 Acyl chain length (ACL) of membrane lipids in Arabidopsis and rice after various low-temperature treatments

\begin{tabular}{|c|c|c|c|c|c|c|c|c|}
\hline \multirow[t]{2}{*}{ Lipid class } & \multirow[t]{2}{*}{ Plant species } & \multirow[b]{2}{*}{ C } & \multicolumn{3}{|c|}{ Arabidopsis $\left(-6^{\circ} \mathrm{C}\right) /$ Rice $\left(10^{\circ} \mathrm{C}\right)$} & \multicolumn{3}{|c|}{ Arabidopsis $\left(-12^{\circ} \mathrm{C}\right) /$ Rice $\left(4^{\circ} \mathrm{C}\right)$} \\
\hline & & & $\mathrm{T}$ & R1 & R3 & $\mathrm{T}$ & $\mathrm{R} 1$ & R3 \\
\hline & & Acyl chain length & (ACL) & & & & & \\
\hline \multirow[t]{2}{*}{ DGDG } & Arabidopsis & $35.56 \pm 0.02^{\mathrm{bc} *}$ & $35.59 \pm 0.08^{\mathrm{abc} *}$ & $35.61 \pm 0.04^{\mathrm{ab} *}$ & $35.63 \pm 0.03^{\mathrm{a} *}$ & $35.54 \pm 0.03^{\mathrm{C*}}$ & $35.47 \pm 0.02^{d *}$ & $35.36 \pm 0.06^{\mathrm{e} *}$ \\
\hline & Rice & $35.80 \pm 0.02^{b}$ & $35.84 \pm 0.03^{\mathrm{a}}$ & $35.80 \pm 0.03^{b}$ & $35.73 \pm 0.02^{c}$ & $35.78 \pm 0.02^{b}$ & $35.87 \pm 0.04^{\mathrm{a}}$ & $35.85 \pm 0.04^{\mathrm{a}}$ \\
\hline \multirow[t]{2}{*}{ MGDG } & Arabidopsis & $34.49 \pm 0.06^{\mathrm{e} *}$ & $34.54 \pm 0.08^{\mathrm{de} *}$ & $34.60 \pm 0.05^{\mathrm{cd} *}$ & $34.57 \pm 0.03^{\text {de* }}$ & $34.65 \pm 0.06^{\mathrm{bc} *}$ & $34.80 \pm 0.08^{\mathrm{a} *}$ & $34.73 \pm 0.07^{\mathrm{ab} *}$ \\
\hline & Rice & $35.97 \pm 0.00^{\mathrm{ab}}$ & $35.98 \pm 0.00^{a}$ & $35.97 \pm 0.00^{b}$ & $35.95 \pm 0.00^{c}$ & $35.98 \pm 0.00^{\mathrm{a}}$ & $35.98 \pm 0.01^{a}$ & $35.95 \pm 0.01^{c}$ \\
\hline \multirow[t]{2}{*}{$P G$} & Arabidopsis & $33.92 \pm 0.02^{a b_{*}}$ & $33.93 \pm 0.01^{\mathrm{a} *}$ & $33.91 \pm 0.02^{\mathrm{ab} *}$ & $33.88 \pm 0.01^{c_{*}^{*}}$ & $33.92 \pm 0.01^{\mathrm{ab} *}$ & $33.90 \pm 0.01^{b *}$ & $33.85 \pm 0.03^{\mathrm{d} *}$ \\
\hline & Rice & $33.51 \pm 0.05^{\mathrm{a}}$ & $33.46 \pm 0.01^{\mathrm{ab}}$ & $33.42 \pm 0.03^{b c}$ & $33.41 \pm 0.02^{b c}$ & $33.52 \pm 0.02^{\mathrm{a}}$ & $33.39 \pm 0.05^{c}$ & $33.20 \pm 0.13^{d}$ \\
\hline \multirow[t]{2}{*}{ PA } & Arabidopsis & $34.73 \pm 0.09^{\mathrm{d} *}$ & $35.00 \pm 0.11^{\mathrm{a}}$ & $34.87 \pm 0.02^{c}$ & $34.84 \pm 0.05^{\mathrm{c}}$ & $34.98 \pm 0.02^{\mathrm{ab} *}$ & $34.90 \pm 0.05^{b c *}$ & $34.73 \pm 0.08^{d}$ \\
\hline & Rice & $34.44 \pm 0.19^{c}$ & $34.93 \pm 0.05^{a}$ & $34.78 \pm 0.17^{b}$ & $34.74 \pm 0.14^{b}$ & $34.73 \pm 0.02^{b}$ & $34.76 \pm 0.03^{b}$ & $34.67 \pm 0.04^{b}$ \\
\hline \multirow[t]{2}{*}{ PC } & Arabidopsis & $35.15 \pm 0.07^{\mathrm{a} *}$ & $35.21 \pm 0.07^{a *}$ & $35.09 \pm 0.04^{\mathrm{abc} * *}$ & $34.94 \pm 0.02^{c *}$ & $35.13 \pm 0.10^{\mathrm{ab}}$ & $34.98 \pm 0.12^{b c}$ & $35.10 \pm 0.27^{\mathrm{abc}}$ \\
\hline & Rice & $34.93 \pm 0.03^{c}$ & $34.95 \pm 0.01^{c}$ & $34.81 \pm 0.01^{d}$ & $34.85 \pm 0.04^{d}$ & $35.08 \pm 0.04^{a}$ & $35.00 \pm 0.02^{b}$ & $35.07 \pm 0.07^{\mathrm{a}}$ \\
\hline \multirow[t]{2}{*}{ PE } & Arabidopsis & $35.36 \pm 0.09^{\mathrm{abc} c *}$ & $35.74 \pm 0.23^{\mathrm{a} *}$ & $35.33 \pm 0.12^{\mathrm{bc*}}$ & $35.21 \pm 0.12^{c}$ & $35.67 \pm 0.26^{\mathrm{ab} *}$ & $35.17 \pm 0.58^{c}$ & $35.11 \pm 0.33^{c}$ \\
\hline & Rice & $35.15 \pm 0.05^{\mathrm{a}}$ & $35.06 \pm 0.06^{b}$ & $35.07 \pm 0.05^{\mathrm{ab}}$ & $35.12 \pm 0.01^{\mathrm{ab}}$ & $35.14 \pm 0.07^{a}$ & $35.06 \pm 0.08^{b}$ & $34.96 \pm 0.09^{c}$ \\
\hline \multirow[t]{2}{*}{$\mathrm{Pl}$} & Arabidopsis & $34.28 \pm 0.04^{\mathrm{ab} *}$ & $34.32 \pm 0.03^{\mathrm{a} *}$ & $34.17 \pm 0.03^{\mathrm{cd} *}$ & $34.13 \pm 0.02^{d *}$ & $34.31 \pm 0.03^{\mathrm{ab} *}$ & $34.26 \pm 0.05^{b *}$ & $34.20 \pm 0.06^{c *}$ \\
\hline & Rice & $34.37 \pm 0.01^{d}$ & $34.50 \pm 0.03^{b}$ & $34.27 \pm 0.03^{e}$ & $34.24 \pm 0.02^{e}$ & $34.67 \pm 0.03^{\mathrm{a}}$ & $34.41 \pm 0.06^{c}$ & $34.35 \pm 0.02^{d}$ \\
\hline \multirow[t]{2}{*}{ PS } & Arabidopsis & $36.92 \pm 0.30^{\mathrm{ab}}$ & $37.07 \pm 0.56^{a}$ & $35.95 \pm 0.47^{\mathrm{bc*}}$ & $36.63 \pm 0.38^{\mathrm{abc} *}$ & $36.24 \pm 0.63^{\mathrm{abc}}$ & $35.77 \pm 0.76^{\mathrm{C*}}$ & $36.87 \pm 1.63^{\mathrm{ab}}$ \\
\hline & Rice & $37.11 \pm 0.24^{b c}$ & $37.32 \pm 0.30^{\mathrm{ab}}$ & $37.57 \pm 0.29^{a}$ & $37.35 \pm 0.17^{\mathrm{ab}}$ & $36.44 \pm 0.30^{e}$ & $36.84 \pm 0.26^{\mathrm{cd}}$ & $36.51 \pm 0.38^{\text {de }}$ \\
\hline \multirow[t]{2}{*}{ Total } & Arabidopsis & $34.66 \pm 0.05^{\mathrm{b} *}$ & $34.76 \pm 0.07^{a b *}$ & $34.76 \pm 0.03^{\mathrm{ab} *}$ & $34.72 \pm 0.01^{b *}$ & $34.86 \pm 0.02^{\mathrm{a} *}$ & $34.70 \pm 0.10^{\mathrm{b} *}$ & $34.46 \pm 0.15^{c *}$ \\
\hline & Rice & $35.73 \pm 0.02^{\mathrm{a}}$ & $35.74 \pm 0.01^{\mathrm{a}}$ & $35.72 \pm 0.01^{\mathrm{a}}$ & $35.73 \pm 0.01^{\mathrm{a}}$ & $35.65 \pm 0.03^{b}$ & $35.52 \pm 0.03^{c}$ & $35.36 \pm 0.09^{d}$ \\
\hline
\end{tabular}

$\mathrm{ACL}=\left(\sum[n \times \mathrm{mol} \%\right.$ lipid] $) / 100, n$ is the total number of carbons in the two fatty acid chains of each glycerolipid molecule. " $\mathrm{C}$ " represents "control", "T" indicates samples taken immediately after each cold treatment, and "R1" and "R3" indicate samples taken after post treatment recovery culture for 1 and 3 days, respectively. Values in the same row marked with different letters are significantly different, while an asterisk means that the value in Arabidopsis is significantly different from that in rice $(p<0.05)$. Values are means \pm SD $(n=4$ or 5$)$ 
Table 3 Double-bond index (DBI) of membrane lipids in Arabidopsis and rice after various low-temperature treatments

\begin{tabular}{|c|c|c|c|c|c|c|c|c|}
\hline \multirow[t]{2}{*}{ Lipid class } & \multirow[t]{2}{*}{ Plant species } & \multirow[b]{2}{*}{ C } & \multicolumn{3}{|c|}{ Arabidopsis $\left(-6^{\circ} \mathrm{C}\right) /$ Rice $\left(10^{\circ} \mathrm{C}\right)$} & \multicolumn{3}{|c|}{ Arabidopsis $\left(-12^{\circ} \mathrm{C}\right) /$ Rice $\left(4^{\circ} \mathrm{C}\right)$} \\
\hline & & & $\mathrm{T}$ & R1 & R3 & $\mathrm{T}$ & R1 & R3 \\
\hline & & \multicolumn{7}{|c|}{ Double-bond index (DBI) } \\
\hline \multirow[t]{2}{*}{ DGDG } & Arabidopsis & $5.34 \pm 0.04^{\mathrm{b} *}$ & $5.41 \pm 0.13^{\mathrm{ab} *}$ & $5.47 \pm 0.05^{\mathrm{a}}$ & $5.49 \pm 0.03^{\mathrm{a} *}$ & $5.41 \pm 0.04^{\mathrm{ab} *}$ & $5.33 \pm 0.06^{\mathrm{b} *}$ & $5.08 \pm 0.14^{c *}$ \\
\hline & Rice & $5.47 \pm 0.02^{b}$ & $5.56 \pm 0.02^{\mathrm{a}}$ & $5.46 \pm 0.01^{b}$ & $5.34 \pm 0.02^{c}$ & $5.49 \pm 0.02^{b}$ & $5.59 \pm 0.03^{\mathrm{a}}$ & $5.49 \pm 0.06^{b}$ \\
\hline \multirow[t]{2}{*}{ MGDG } & Arabidopsis & $5.94 \pm 0.01^{\mathrm{a} *}$ & $5.93 \pm 0.02^{\mathrm{a} *}$ & $5.89 \pm 0.01^{b *}$ & $5.92 \pm 0.03^{\mathrm{ab} *}$ & $5.93 \pm 0.02^{\mathrm{ab}}$ & $5.81 \pm 0.04^{\mathrm{C*}}$ & $5.74 \pm 0.05^{d *}$ \\
\hline & Rice & $5.89 \pm 0.01^{\mathrm{b}}$ & $5.89 \pm 0.01^{b}$ & $5.83 \pm 0.01^{c d}$ & $5.84 \pm 0.01^{c}$ & $5.92 \pm 0.00^{\mathrm{a}}$ & $5.90 \pm 0.01^{b}$ & $5.82 \pm 0.03^{d}$ \\
\hline \multirow[t]{2}{*}{$P G$} & Arabidopsis & $3.16 \pm 0.08^{\mathrm{a} *}$ & $3.15 \pm 0.11^{a *}$ & $3.09 \pm 0.08^{\mathrm{a} *}$ & $3.09 \pm 0.10^{\mathrm{a} *}$ & $3.11 \pm 0.04^{a *}$ & $3.12 \pm 0.06^{\mathrm{a} *}$ & $2.97 \pm 0.08^{b *}$ \\
\hline & Rice & $2.71 \pm 0.04^{\mathrm{a}}$ & $2.56 \pm 0.02^{b}$ & $2.40 \pm 0.05^{c}$ & $2.39 \pm 0.04^{c}$ & $2.58 \pm 0.08^{b}$ & $2.35 \pm 0.11^{c}$ & $2.20 \pm 0.10^{d}$ \\
\hline \multirow[t]{2}{*}{ PA } & Arabidopsis & $3.36 \pm 0.13^{\mathrm{d} *}$ & $4.24 \pm 0.23^{\mathrm{a} *}$ & $3.81 \pm 0.12^{\mathrm{b} *}$ & $3.58 \pm 0.16^{c *}$ & $3.82 \pm 0.07^{\mathrm{b} *}$ & $3.77 \pm 0.04^{\mathrm{b} *}$ & $3.39 \pm 0.08^{d *}$ \\
\hline & Rice & $2.79 \pm 0.18^{c}$ & $3.16 \pm 0.10^{b}$ & $2.93 \pm 0.20^{c}$ & $2.95 \pm 0.19^{c}$ & $3.32 \pm 0.06^{\mathrm{ab}}$ & $3.42 \pm 0.05^{\mathrm{a}}$ & $3.21 \pm 0.06^{b}$ \\
\hline \multirow[t]{2}{*}{ PC } & Arabidopsis & $3.77 \pm 0.04^{\mathrm{ab} *}$ & $4.03 \pm 0.15^{a *}$ & $3.84 \pm 0.11^{\mathrm{ab} *}$ & $3.73 \pm 0.06^{\mathrm{ab} *}$ & $3.73 \pm 0.13^{a b *}$ & $3.54 \pm 0.09^{\mathrm{b} *}$ & $3.60 \pm 0.58^{b}$ \\
\hline & Rice & $3.17 \pm 0.02^{c}$ & $3.17 \pm 0.01^{c}$ & $3.03 \pm 0.04^{d}$ & $3.05 \pm 0.04^{d}$ & $3.36 \pm 0.03^{\mathrm{a}}$ & $3.28 \pm 0.06^{b}$ & $3.26 \pm 0.06^{b}$ \\
\hline \multirow[t]{2}{*}{ PE } & Arabidopsis & $3.51 \pm 0.08^{\mathrm{ab} *}$ & $3.65 \pm 0.11^{\mathrm{a} *}$ & $3.51 \pm 0.12^{\mathrm{ab} *}$ & $3.49 \pm 0.05^{\mathrm{abc} *}$ & $3.29 \pm 0.09^{\mathrm{c} *}$ & $2.99 \pm 0.18^{d}$ & $3.39 \pm 0.29^{b c *}$ \\
\hline & Rice & $3.17 \pm 0.03^{b}$ & $3.12 \pm 0.02^{b}$ & $3.18 \pm 0.03^{b}$ & $3.26 \pm 0.05^{\mathrm{a}}$ & $3.12 \pm 0.02^{b}$ & $3.00 \pm 0.08^{c}$ & $3.03 \pm 0.07^{c}$ \\
\hline \multirow[t]{2}{*}{$\mathrm{Pl}$} & Arabidopsis & $2.78 \pm 0.02^{b}$ & $2.99 \pm 0.08^{\mathrm{a} *}$ & $2.82 \pm 0.07^{b *}$ & $2.79 \pm 0.04^{b *}$ & $2.78 \pm 0.03^{b *}$ & $2.80 \pm 0.01^{b_{*}}$ & $2.65 \pm 0.10^{c_{*}}$ \\
\hline & Rice & $2.78 \pm 0.04^{c}$ & $2.86 \pm 0.03^{b}$ & $2.61 \pm 0.03^{d}$ & $2.60 \pm 0.01^{d}$ & $3.19 \pm 0.06^{\mathrm{a}}$ & $2.90 \pm 0.06^{b}$ & $2.79 \pm 0.03^{c}$ \\
\hline \multirow[t]{2}{*}{ PS } & Arabidopsis & $2.62 \pm 0.06^{\mathrm{a} *}$ & $2.74 \pm 0.12^{a_{*}}$ & $2.74 \pm 0.08^{\mathrm{a} *}$ & $2.64 \pm 0.08^{\mathrm{a} *}$ & $2.78 \pm 0.26^{a *}$ & $2.71 \pm 0.09^{\mathrm{a} *}$ & $2.49 \pm 0.59^{a}$ \\
\hline & Rice & $2.47 \pm 0.03^{\mathrm{a}}$ & $2.41 \pm 0.10^{\mathrm{ab}}$ & $2.41 \pm 0.05^{\mathrm{ab}}$ & $2.45 \pm 0.05^{\mathrm{a}}$ & $2.47 \pm 0.10^{a}$ & $2.34 \pm 0.08^{b}$ & $2.43 \pm 0.05^{\mathrm{ab}}$ \\
\hline \multirow[t]{2}{*}{ Total } & Arabidopsis & $5.58 \pm 0.04^{\mathrm{a} *}$ & $5.46 \pm 0.06^{\mathrm{b} *}$ & $5.46 \pm 0.02^{\mathrm{b} *}$ & $5.54 \pm 0.05^{\mathrm{ab} *}$ & $4.33 \pm 0.07^{\complement *}$ & $4.08 \pm 0.11^{\mathrm{d} *}$ & $4.08 \pm 0.15^{d *}$ \\
\hline & Rice & $5.40 \pm 0.04^{\mathrm{a}}$ & $5.39 \pm 0.02^{\mathrm{a}}$ & $5.33 \pm 0.02^{\mathrm{ab}}$ & $5.39 \pm 0.01^{\mathrm{a}}$ & $5.26 \pm 0.07^{b}$ & $5.01 \pm 0.07^{c}$ & $4.71 \pm 0.17^{d}$ \\
\hline
\end{tabular}

$\mathrm{DBI}=(\Sigma[N \times \mathrm{mol} \%$ lipid $]) / 100, N$ is the total number of double bonds in the two fatty acid chains of each glycerolipid molecule. " $\mathrm{C}$ " represents "control", " $\mathrm{T}$ " indicates samples taken immediately after each cold treatment, and "R1" and "R3" indicate samples taken after post treatment recovery for 1 and 3 days, respectively. Values in the same row marked with different letters are significantly different, while an asterisk means that the value in Arabidopsis is significantly different from that in rice $(p<0.05)$. Values are means \pm SD $(n=4$ or 5$)$

composition differed from those for lipid content (Fig. 2a and b). PC1 was represented mainly by PA, PG and PI (Additional file 1: Table S2), and PC2 was represented by DGDG, MGDG and phosphatidylserine (PS). This analysis also indicated a clear separation between Arabidopsis samples subject to freezing-induced lethal treatment and all other samples (PC1). Along PC2, dead samples and live samples were clearly separated.

To appreciate the overall effects of freezing and chilling injury and subsequent recovery, hierarchical clustering of the lipid profiles was applied (Fig. 3). With respect to the non-lethal low-temperature treatment, the lipid profiles of the samples after treatment were similar to those of the control, except for PI, which increased after treatment in Arabidopsis (Fig. 3 Columns $\mathrm{C}$ and $\mathrm{T}\left(6^{\circ} \mathrm{C}\right)$ ) and rice (Columns $\mathrm{C}$ and $\mathrm{T}\left(10{ }^{\circ} \mathrm{C}\right)$ ). Substantial lipid degradation did not occur in Arabidopsis during the period of recovery culture. However, in rice, marked phospholipid degradation occurred during the recovery growth period. In the treatments at lethal low temperatures, freezing-induced lipid degradation in Arabidopsis was more severe than chilling-induced lipid degradation in rice. In addition, in rice, the levels of some molecules of PE and PS even increased after treatment (Fig. 3, Columns $\mathrm{C}$ and $\mathrm{T}\left(4{ }^{\circ} \mathrm{C}\right)$ ).
Lipid degradation during low-temperature treatment and subsequent recovery culture in Arabidopsis and rice

After non-lethal low-temperature treatment $(\mathrm{T})$, the levels of total lipids decreased to $78 \%$ and $80 \%$ of the control (C) levels in Arabidopsis and rice, respectively (Table 1 and Additional file 1: Table S3). These decreases in total lipids were due mostly to the degradation of MGDG, which was the most abundant of the lipids tested (Table 1). In Arabidopsis, PS was the group of lipids that decreased the most, by more than $50 \%$. In contrast, in rice, PG decreased by $44 \%$, which was the largest drop. The level of DGDG rose after treatment at a non-lethal low temperature in both plants. PA levels, which can be increased by low temperature stress and as a degradation product, reached 9.25 and 2.71-times the control levels after treatment of Arabidopsis and rice, respectively (Fig. 4). After recovery culture for 3 days, the total lipids in Arabidopsis rose to $93 \%$ of the control level, and this value was $91 \%$ in rice. The level of most glycerolipids, except for PG, reached at least $90 \%$ of the control levels in Arabidopsis. However, in rice, most lipids, including PG, PA, PC and PC only reached about $70 \%$ of the control levels. PG recovered the slowest; after 3 days of recovery culture, its levels were $87 \%$ and 

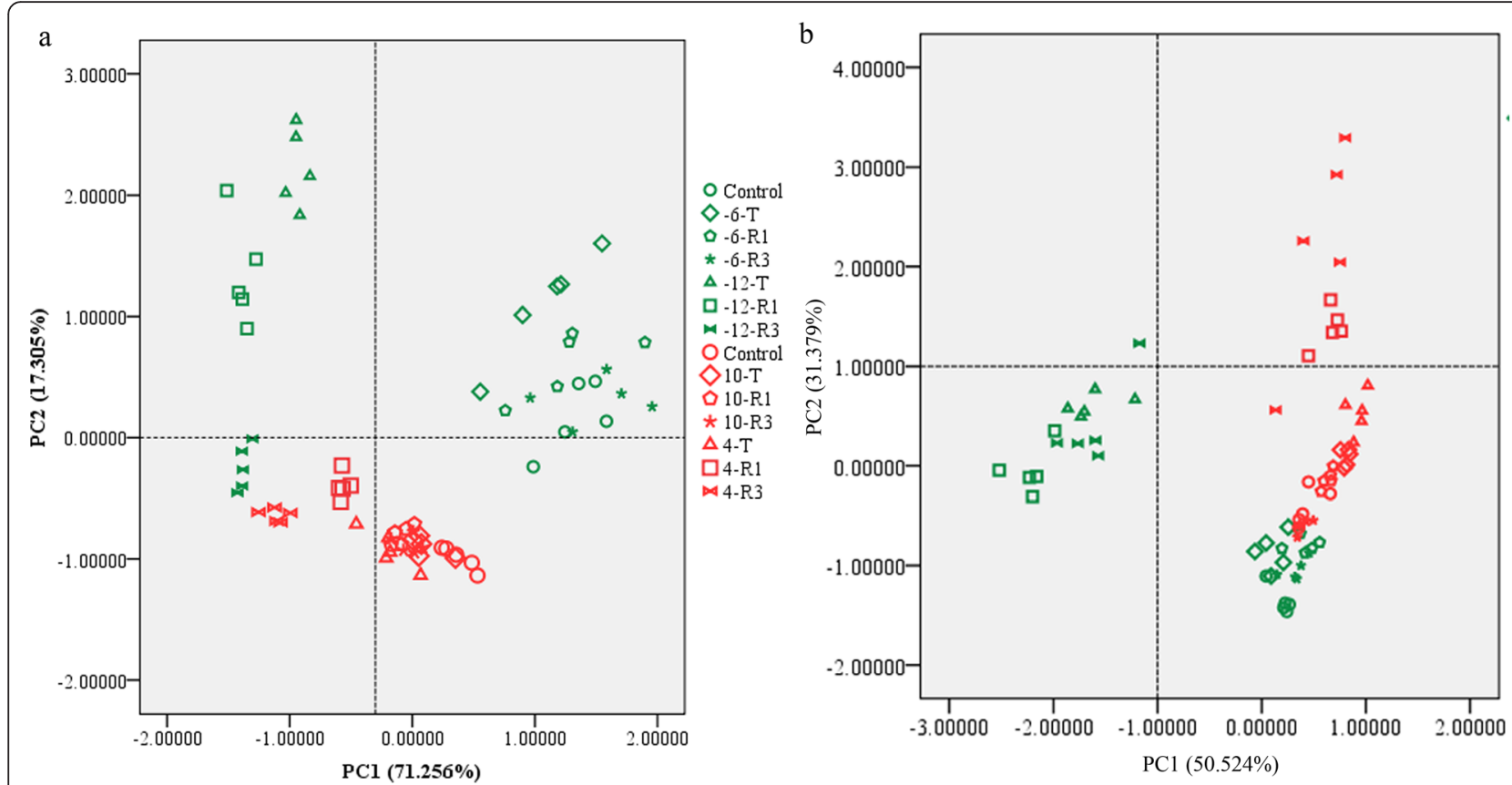

Fig. 2 Principal component analysis (PCA) of the lipid composition upon different low-temperature treatments of Arabidopsis and rice. a PCA analysis of lipid content (nmol per mg). b PCA analysis of lipid relative content (mol\%). Green and red symbols represent Arabidopsis and rice, respectively. The different treatments are represented by different shapes. $-6,-12,10$ and 4 represent temperatures of treatment in ${ }^{\circ} \mathrm{C}$. $-6^{\circ} \mathrm{C}$ and $10^{\circ} \mathrm{C}$ are non-lethal low temperatures for Arabidopsis and rice, while $-12^{\circ} \mathrm{C}$ and $4{ }^{\circ} \mathrm{C}$ are lethal low temperatures for Arabidopsis and rice, respectively. T represents samples immediately after low-temperature treatment, R1 and R3 represent samples after 1 and 3 days of recovery growth

$56 \%$ in Arabidopsis and rice, respectively (Table 1 and Additional file 1: Table S3).

Treatment at lethal low temperatures induced severe lipid degradation in both Arabidopsis and rice. The content of total lipids in Arabidopsis decreased by $80 \%$, while it decreased by $40 \%$ in rice (Table 1). However, the levels of some lipids increased after treatment. The content of PI increased in Arabidopsis and that of PE increased in rice. PA in Arabidopsis rose to about 100times its level in the control and its level in rice rose to about 20-times the control level (Fig. 4). The severe degradation of glycerolipids and the considerable increase in PA level in Arabidopsis after lethal freezing treatment suggest that the rise of PA was due in part to the degradation of other glycerolipids.

\section{Lipid profile changes during low-temperature treatment of Arabidopsis and rice}

Detailed analyses of the lipid profiles indicated that the changes in phospholipids, galactolipids and lysophospholipids in the two plants were similar during nonlethal low-temperature treatment (Figs. 5 and 6). There were, however, minor differences between the two plants in PG species 32:1, 34:3 and 34:4; PC species 34:3 and 34:6; 34:3 PI; 34:3 PS; and lysoPG species 16:0 and 18:3. The trends in the responses of 36:6 MGDG and 36:6
DGDG to non-lethal treatment were similar in Arabidopsis and rice, while the change in 36:6 MGDG differed from that of 36:6 DGDG during treatment. The level of 36:6 DGDG rose after treatment and reached the level of the control after 3 days of recovery culture. However, the level of 36:6 MGDG decreased after cold treatment then rose to the level of the control after recovery culture (Fig. 5; Additional file 1: Table S1). The 34:1 PG content did not show any marked changes, whereas the level of 34:4 PG decreased dramatically, especially in rice (Fig. 5; Additional file 1: Table S4).

The trends in the response of the glycerolipidome to lethal low-temperature treatment were similar in Arabidopsis and rice (Figs. 5 and 6). Interestingly, during such treatments, we detected some PA molecules that could not be detected in the non-lethal treatment, such as 32:0, 36:2 and 36:3 PA in both species, and 34:5 PA in Arabidopsis (Fig. 5; Additional file 1: Table S5). Lowtemperature treatment could induce the generation of 34:6 PA in Arabidopsis, but we could not detect this lipoid molecule at all in rice. We hypothesize that 34:6 PA in Arabidopsis is generated by the degradation of 34:6 MGDG. In Arabidopsis, the trends of changes of PI species $34: 2,34: 3$ and 36:5 were similar to those of the corresponding lipid species of PA. It was shown that 34:2 and 34:3 PI are the most abundant PI species in 


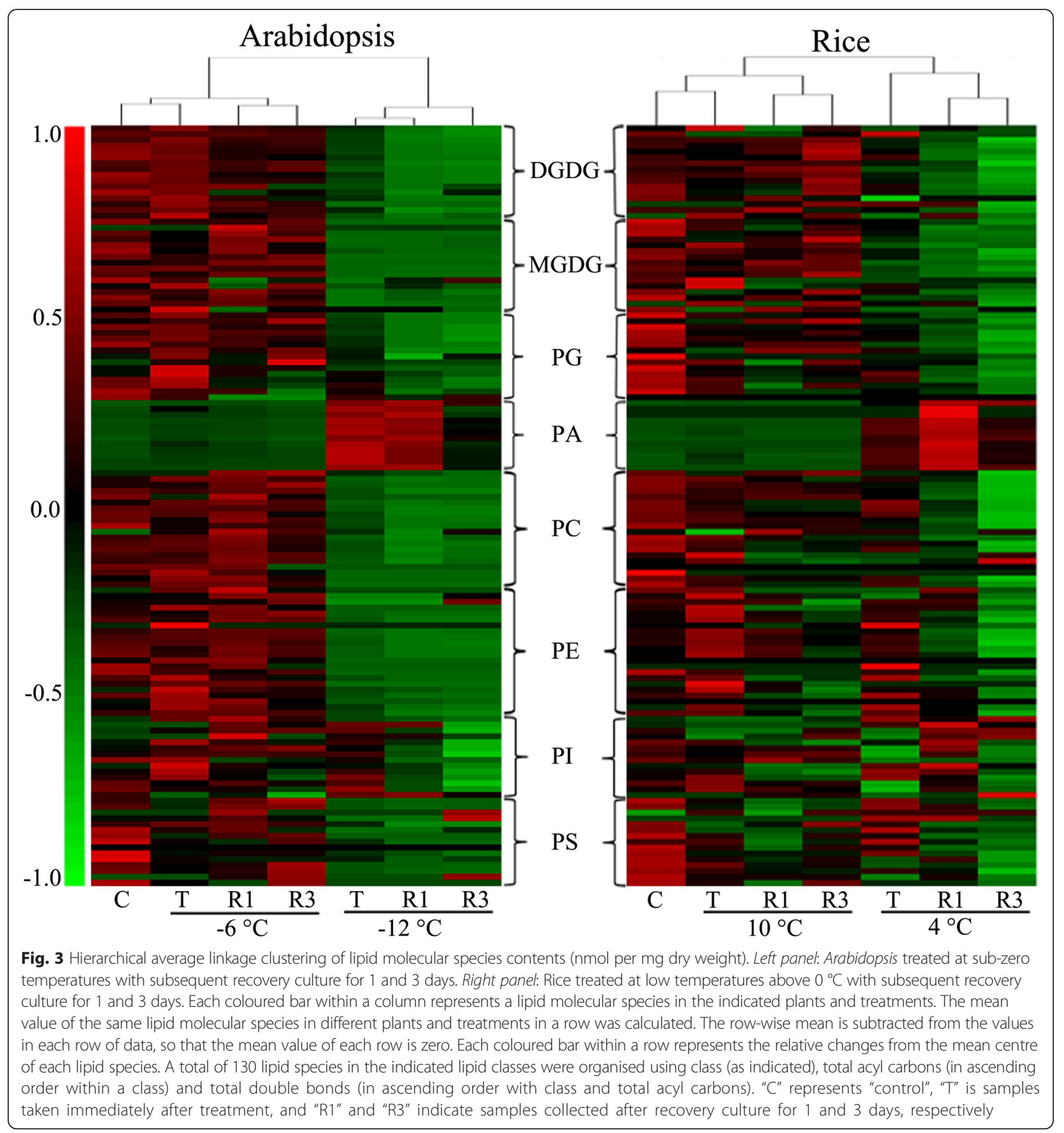

Arabidopsis; they increased after freezing and decreased dramatically thereafter during the recovery culture period. Meanwhile, in rice, the levels of these two PI species decreased after chilling and then increased considerably after 1 day of recovery culture (Fig. 5). Most of the lysoPC and lysoPE species increased dramatically in both plants during low-temperature treatment (Fig. 6). This might indicate that the degradation of PC and PE might be carried out partly by phospholipase A during lowtemperature-induced death.

Total levels of ACL and unsaturation of membrane glycerolipids were maintained during low-temperature treatment in both Arabidopsis and rice

We used ACL and DBI to represent the fluidity of membranes. A low ACL and a high DBI increase the fluidity 


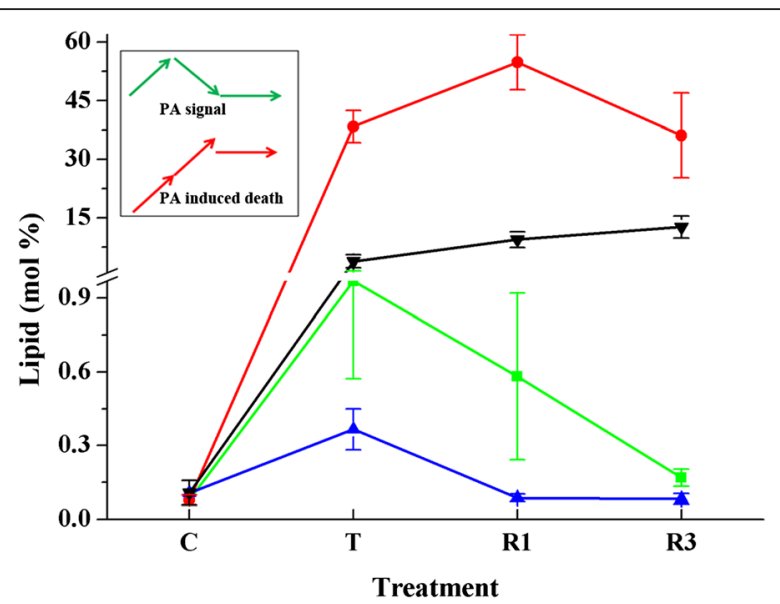

Fig. 4 Relative content (mol \%) of PA in leaves of Arabidopsis and rice after various low-temperature treatments. Inset, models of PA change during non-lethal (green arrow) and lethal (red arrow) low temperature treatment. Green line, Arabidopsis treated at non-lethal low temperature. Blue line, rice treated at non-lethal low temperature. Red line, Arabidopsis treated at lethal low temperature. Black line, rice treated at lethal low temperature. " $\mathrm{C}$ " represents "control", "T" is sample taken immediately after treatment, and "R1"and "R3" indicate samples collected after recovery culture for 1 and 3 days, respectively. Values are means \pm S.D. $(n=4$ or 5$)$

of a membrane. The degree of ACL of most lipid classes and of total lipids was maintained during non-lethal and lethal low-temperature treatments, except for that of PA and PS (Table 2). The ACL of PA increased in both plants, which might indicate that lipids with long fatty acid chains were degraded to PA. After recovery culture for 1 day following non-lethal low-temperature treatment, the ACL of PS decreased by almost one carbon in Arabidopsis, while it increased by almost 0.5 carbons in rice. The ACL of PS in both plants decreased during lethal low-temperature treatment (Table 2).

A high DBI indicates the presence of more highly unsaturated membrane lipids, and vice versa [15]. During non-lethal low-temperature treatment, the DBI of most glycerolipids was maintained, except for PA and PG (Table 3). The DBI of PG decreased in rice and was maintained in Arabidopsis. The DBI of PA in both plants increased after treatment and during the subsequent recovery culture period, but this increase was much greater in Arabidopsis than in rice (Table 3). During lethal low-temperature treatment, the DBI of total membrane lipids of Arabidopsis decreased dramatically immediately after treatment, and decreased further during the subsequent recovery culture process. This decrease was due mainly to the decrease of the DBI of the most abundant lipids, such as PE (Tables 1 and 3). After 3 days of recovery culture, compared to the control level, the DBI of most lipids decreased, except for PA. The DBI of the total membrane lipids also decreased dramatically in rice. These results indicate that the degree of unsaturation of membrane glycerolipids was maintained in Arabidopsis and rice during non-lethal low-temperature treatment, and that the lipid degradation induced by lethal low-temperature treatments might have involved the degradation of lipids with more double bonds first.

\section{Discussion}

The responses of plants to low temperatures, especially their acclimation to cold, have been investigated extensively. Transcriptional factors, such as CBF, play important roles in Arabidopsis and rice responses to low temperatures [29]. Membranes are the initial temperature sensors, and remodelling of membrane lipids is one of the most important mechanisms used by plants to respond to low temperatures $[13,18]$. Low temperature could induce the decrease of sterols in chilling sensitive plants, for example Vigna angularis [30]. Few studies have used lipidomic approaches to investigate the different influences of plant injuries induced by low temperatures below $0{ }^{\circ} \mathrm{C}$ (freezing) and above $0{ }^{\circ} \mathrm{C}$ (chilling) on cellular glycerolipid profiles on a large scale $[12,22]$. Most of these previous studies exclusively used Arabidopsis, a species that can tolerate sub-zero low temperatures $[13,19]$, as the test plant. Some plants, such as rice and cucumber, cannot even endure low temperatures above freezing $\left(4^{\circ} \mathrm{C}\right)$, but little is known about how their lipid profiles respond to chilling-induced plant injury. In the study reported herein, we used rice and Arabidopsis to investigate the lipidomic response to chilling- and freezing-induced cell injury.

16:3 and 18:3 plants have different lipid synthesis pathways. It has been shown that $16: 3$ and $18: 3$ plants have similar lipid and fatty acid compositions, except for 34:6 MGDG, which is not present in the latter group [15]. $\mathrm{Li}$ et al. found that the prokaryotic-type lipid synthesis pathway was upregulated by low temperature and the eukaryotic-type pathway was promoted by high temperature in Arabidopsis [31]. Rice is an 18:3 plant, which is chilling-sensitive, while Arabidopsis is a freezingtolerant 16:3 plant. Against this background, the following question arises: do the different pathways for lipid synthesis contribute to the differences between Arabidopsis and rice in their capacity to tolerate low temperatures? The content of polyunsaturated lipids and the degree of unsaturation of lipids are two important factors that affect plant tolerance of low temperatures $[15,32]$. The particular lipid synthesis pathway used by a plant does not affect its trienoic acid content or its degree of lipid unsaturation $[15,33,34]$. Solanum nodiflorum and Spinacia oleracea are 16:3 plants that are cold-sensitive, whereas Saussurea medusa, which is an 18:3 plant, can tolerate sub-zero low temperatures in alpine screes [15]. Thus, the differences in 

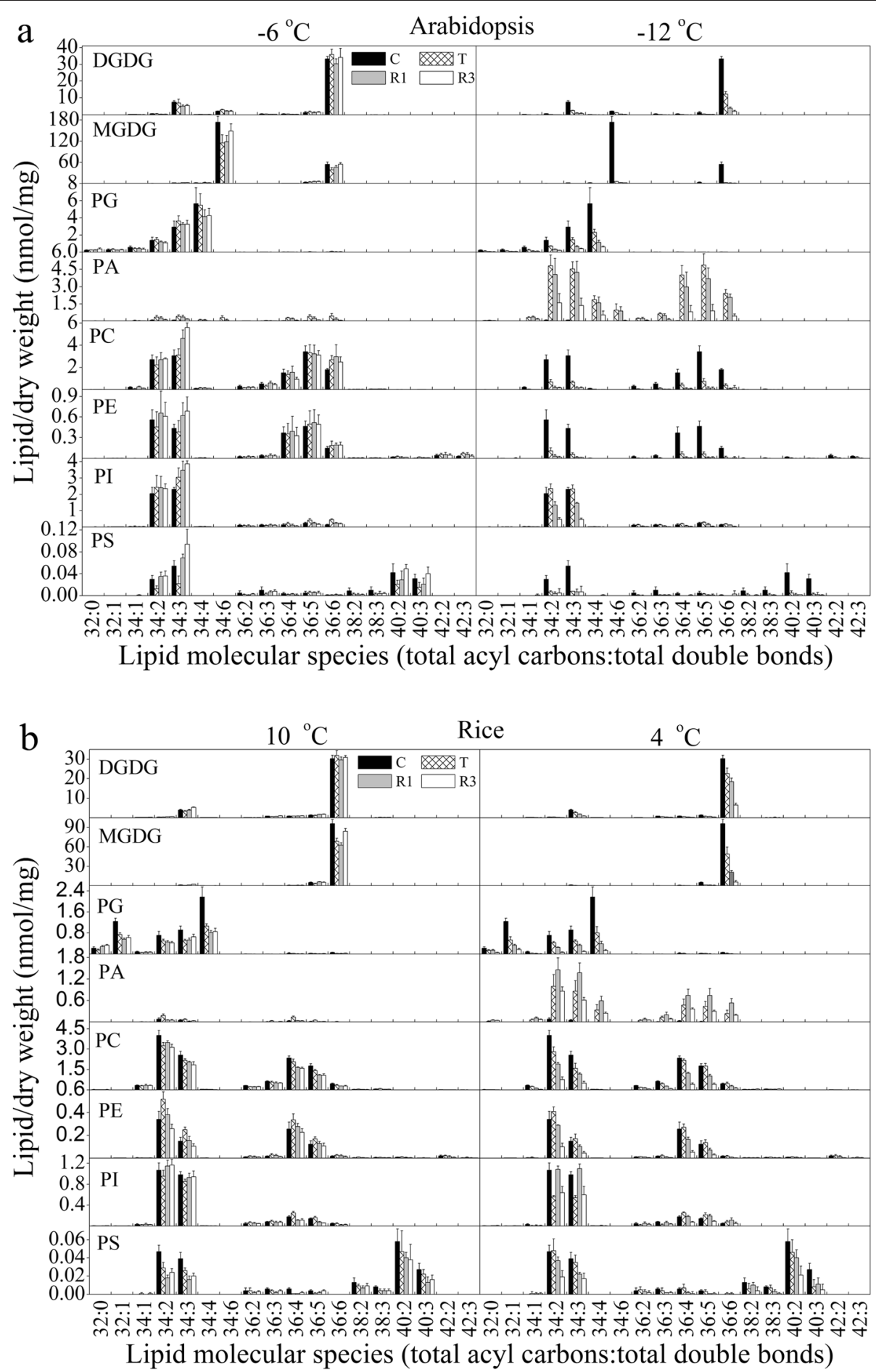

Fig. 5 Changes in lipid molecular species during various cold treatments and subsequent recovery culture of Arabidopsis (a) and rice (b). a Left panel: galactolipids and phospholipids of Arabidopsis after $-6{ }^{\circ} \mathrm{C}$ treatment; right panel, galactolipids and phospholipids of Arabidopsis after $-12{ }^{\circ} \mathrm{C}$ treatment. b Left panel: galactolipids and phospholipids of rice after $10^{\circ} \mathrm{C}$ treatment; right panel, galactolipids and phospholipids of rice after $4{ }^{\circ} \mathrm{C}$ treatment. The dry weight is the $d r y$ weight minus lipids (i.e., the dry weight after lipid extraction). " $\mathrm{C}$ " means control, "T" indicates samples taken immediately after each cold treatment, and "R1" and "R3" indicate samples taken after posttreatment recovery culture for 1 and 3 days, respectively. Values are means \pm S.D. $(n=5)$ 

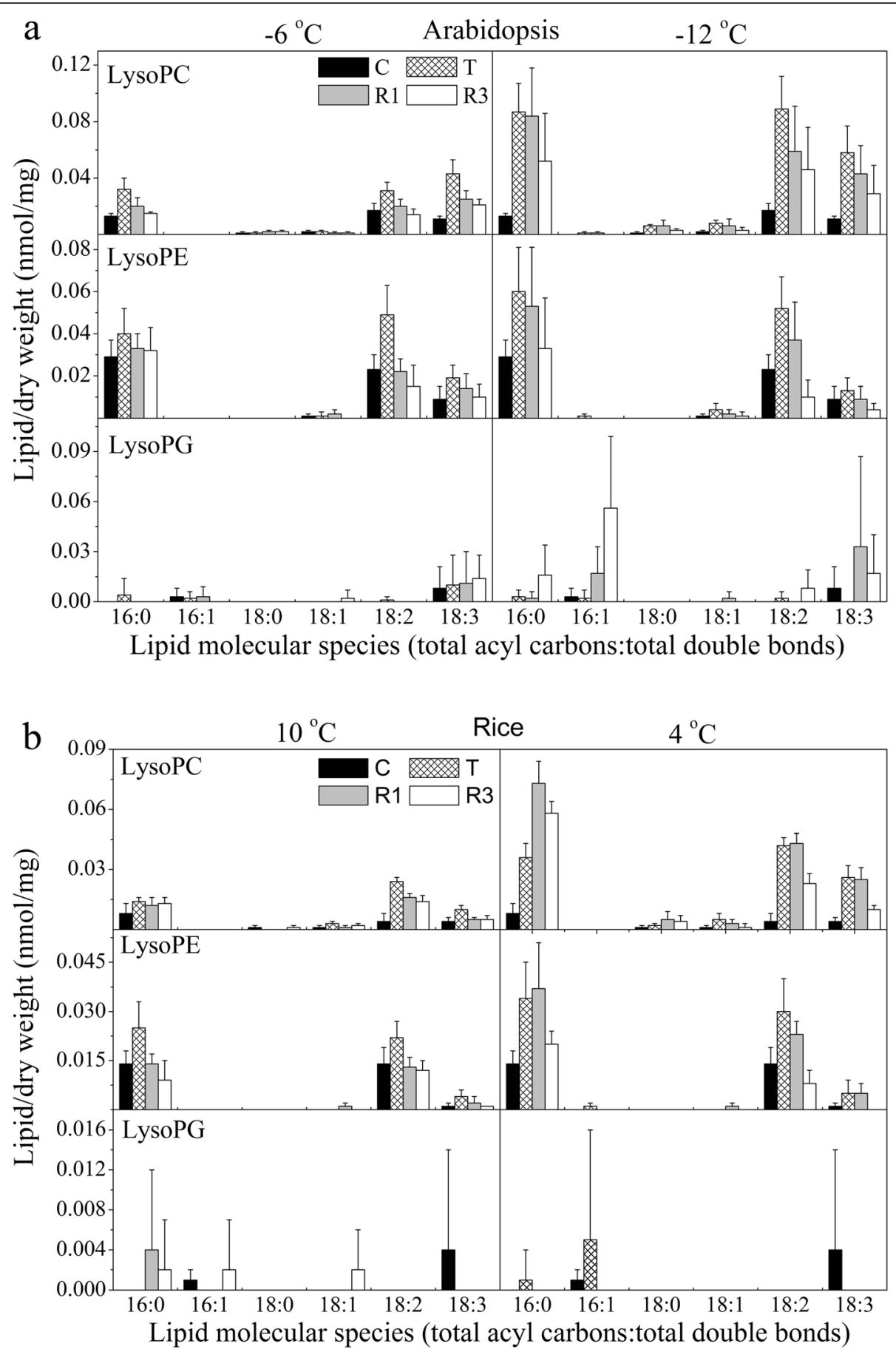

Fig. 6 Changes in lysophospholipid molecular species during various cold treatments and subsequent recovery culture of Arabidopsis (a) and rice (b). a Left panel: galactolipids and phospholipids of Arabidopsis after $-6{ }^{\circ} \mathrm{C}$ treatment; right panel: galactolipids and phospholipids of Arabidopsis after $-12{ }^{\circ} \mathrm{C}$ treatment. $\mathbf{b}$ Left panel: galactolipids and phospholipids of rice after $10{ }^{\circ} \mathrm{C}$ treatment; right panel, galactolipids and phospholipids of rice after $4^{\circ} \mathrm{C}$ treatment. The dry weight is the dry weight minus lipids (i.e., the dry weight after lipid extraction). "C" means control, "T" indicates samples taken immediately after each cold treatment, and "R1" and "R3" indicate samples taken after posttreatment recovery culture for 1 and 3 days, respectively. Values are means \pm S.D. $(n=5)$

lipid synthesis between Arabidopsis and rice might not contribute to the differences in these two plants' capacities to tolerate low temperatures.
The ACL and DBI of membrane glycerolipids are two important factors that determine the fluidity of membranes. Fatty acids with longer chains and a lower DBI 
can make the membrane environment more gel-like $[15,35]$. It has been reported that the ACL decreases in low-temperature grown bacteria [36] and the DBI tends to increase in plants at low temperatures [37]. In this work, the ACL of the total lipids of cold acclimated Arabidopsis was shown to be one carbon less than that in normal growth rice, and the levels of DBI of most phospholipids and MGDG of Arabidopsis were higher than in rice. This lower ACL and higher DBI of Arabidopsis may give its membranes more fluidity under low-temperature stress, which makes this plant more tolerant to low-temperature. However, the $\mathrm{ACL}$ and DBI changed little during low-temperature treatment in either plant. Time and energy are required to change the ACL and DBI. For example, the synthesis of fatty acids from acetyl-CoA and malonyl-CoA requires at least 30 enzymatic reactions [38]. Alteration of the degree of saturation of glycerolipids requires more energy than glycerolipid turnover and is a response of plants to longterm extreme temperatures [15]. In light of this, we conjecture that adjustments of the levels of ACL are also long-term adaptations by plants to extreme temperatures.

Fatty acids with chain lengths of 16 and 18 carbons are the major fatty acids in plants [38]. Most glycerolipids are first synthesized using only palmitic acid (16:0) and oleic acid (18:1), and acyltransferases, including those involved in glycerolipid synthesis, preferentially incorporate these two fatty acids [39, 40]. Glycerolipids that contain 34 and 36 acyl carbons were the most common groups among the lipids determined in our lipidomic investigation, and glycerolipids containing VLCFAs were less abundant. VLCFAs are synthesized in the endoplasmic reticulum (ER) through fatty acid elongase (FAE) complexes starting from 18-carbon chains [28], and FAE is not expressed in vegetative tissues [41]. Burgos et al. considered that glycerolipids with VLCFAs are almost exclusively extrachloroplastic [42]. However, we found some chloroplastic glycerolipids with VLCFAs and the relative content of these lipids was almost double that of extrachloroplastic VLCFA-containing glycerolipids. Overexpression of the FAE1 gene could induce the accumulation of VLCFAs in the galactolipids of chloroplast membranes [43]. The synthesis of galactolipids with VLCFAs may occur either through VLCFA transport from the ER to chloroplast membranes, or through glycerolipid turnover instead of via a de novo synthesis pathways in chloroplast membranes. In a previous study, we found that, among eight glycerolipid classes, the ACL of PS was the highest and showed high diversity in different plant species, and that it increased during plant development and under environmental stresses [44]. Millar et al. considered that the accumulation of VLCFAs is deleterious to cells because they can perturb the integrity of membrane structures [45]. The ACL of PS increased in both Arabidopsis and rice during non-lethal lowtemperature treatment, and then decreased rapidly in Arabidopsis after treatment. The capacity to remove very long fatty acids of PS in Arabidopsis plants under low-temperature stress may contribute to their greater low-temperature tolerance than rice.

PG is the major phospholipid in chloroplast membranes, and the composition of PG molecular species is correlated closely with the sensitivity of plants to low temperatures. Plants that have more PG molecules with a high melting point, such as 16:0/16:0 (32:0) and 16:0/ 16:1(3t) (32:1), are sensitive to low-temperature stresses $[26,27]$. In our previous study, we found that the level of high-melting-point PG molecules in alpine plants was very low [15]. The abundance of high-melting-point PG molecules in rice chloroplast membranes might make these membranes more gel-like, preventing tolerance of low-temperature stresses at above $0{ }^{\circ} \mathrm{C}$. This could well be one important factor that contributes to the difference between Arabidopsis and rice in the capacity to tolerate low temperature.

Galactolipids, such as MGDG and DGDG, are the main components of chloroplast membranes, which play an important role in photosynthesis [46]. The ratio of MGDG to DGDG is crucial for the physical phase of thylakoid membranes and might be adjusted as a response to temperature stresses. DGDG has relatively large head groups, which have the propensity to form bilayer membranes, and the transformation of MGDG into DGDG has been shown to be one of the most important mechanisms by which plants respond to freezing stresses [18]. An Arabidopsis mutant with a high ratio of MGDG/DGDG was more sensitive to heat stresses [47]. Surprisingly, even though the capacity of Arabidopsis to tolerate low temperatures was greater than that of rice, the ratio of MGDG/ DGDG in Arabidopsis was far higher than that in rice. Mishra found that the MGDG/DGDG ratio was correlated with the stage of development of plants [48]. However, the decrease of the ratio of MGDG/DGDG in Arabidopsis was higher than that in rice after nonlethal low-temperature treatment. We speculate that the MGDG/DGDG ratio may not be a determinant of low-temperature tolerance between different plant species, but that the capacity of plants to regulate their MGDG/ DGDG ratio may be positively correlated with tolerance of low temperatures.

PI is the third most abundant extraplastidic lipid. It is a precursor for inositol-containing lipids. PI and its derivatives, polyphosphoinositides, play important roles in stress responses [49-51]. In our experiments, the DBI and ACL of PI were found to be highly conserved, with no differences between Arabidopsis and rice during treatment. Most glycerolipids were degraded after low-temperature treatment, but the content of PI in 
Arabidopsis increased by about $50 \%$ after freezing. However, it remained unchanged in rice after chilling treatment. Liu found that the overexpression of PI synthase could improve drought tolerance in maize [52]. Both freezing and drought can induce osmotic stress in plants, so PI or its derivatives might participate in plant responses to freezing-induced osmotic stress. The capacity to synthesise PI at low temperatures may correlate with the sensitivity of plants to low temperatures. Little is known about signals transduced by PI and its derivatives under freezing stresses, so further studies should be performed using mutants to investigate the relationship between the level of PI and the capacity of plants to tolerate low temperatures.

PA is a very important glycerolipid. It is an intermediate in glycerolipid synthesis and degradation [36, 53]. It also acts as a signalling lipid that participates extensively in the closure of stomata and in stress responses in plants [24, 54-56]. However, the accumulation of PA can compromise membrane integrity because it has a cone-like geometry and a tendency to form the hexagonal II phase of membranes [16, 19]. Low temperature induced an increase of PA in both Arabidopsis and rice. Immediately after lethal low-temperature treatment, PA reached 98 and 20-times the control levels in Arabidopsis and rice, respectively, which was far higher than the increase induced by non-lethal low temperatures. The non-lethal low temperature-induced rise in PA could be countered in the recovery culture period. However, the increased PA pool induced by lethal low temperatures was too great for the plants to remove, resulting in a very large PA pool in cells.

We speculate that the ability to remove the lowtemperature-induced PA pool is related closely to plants' capacity to tolerate low temperatures. The accumulation of PA could lead to lesions and loss of the osmoregulatory capacity of membranes; finally, water would flood into cells, causing them to burst. Low-temperatureinduced PA accumulation in plant cells may thus be the main reason for cell damage. PA may play dual roles in both chilling and freezing stresses (Fig. 4): during nonlethal low temperature treatment, PA may act as a signal; its level increased greatly immediately after treatment, then decreased to the level of the control during the recovery process. However, on lethal low temperature treatment, PA increased significantly and was maintained at a very high level, inducing cell death.

\section{Conclusions}

This paper describes the response of glycerolipidome to chilling and freezing induced injuries in chillingsensitive plant rice and freezing-tolerant plant Arabidopsis respectively. The two plants have different lipid synthesis pathways, which rice is an 18:3 plant and
Arabidopsis is a 16:3 plant, however, this difference between the two plants may not correlate to their different low temperature tolerant ability. Arabidopsis has higher levels of galactolipids and DBI, and lower levels of ACL than rice, which may be one important reason for its more low temperature tolerance ability. The speed of removing VLCFAs of PS in Arabidopsis is quicker than that in rice, which could reduce the VLCFAs caused injuries in cells. The decrease of the rate of MDGD/DGDG is higher in Arabidopsis than that in rice, and this may contribute to maintain the integrity of chloroplast membranes during low temperature stress. The ability of plants to regulate the ratio of MGDG/DGDG may be one important determinant to low temperature tolerant ability in plants. Low temperature induces the rise of PA, and PA may play dual roles during low temperature stress, which as a signal lipid helping plants tolerate to low temperatures, or as a structural molecule leading to lesions in membranes and finally causing the cell death.

\section{Methods}

\section{Plant materials and treatments}

Seeds of Arabidopsis (Arabidopsis thaliana) were of the Wassilewskija ecotype and collected from plants bred in our experimental lab. Rice (Oryza sativa indica) seeds were purchased from Jingdian Seed Company (Kunming, China). For Arabidopsis, seeds were cold-stratified at $4{ }^{\circ} \mathrm{C}$ for 3 days before culture. All plants were grown in soil (humus soil:clay 4:1) and watered every week; one-quarter Hoagland solution was added to soil every month. The normal growth conditions were $22{ }^{\circ} \mathrm{C}$ (day) and $18{ }^{\circ} \mathrm{C}$ (night) with fluorescent lighting of $120 \mu \mathrm{mol} \cdot \mathrm{m}^{-}{ }^{2} \cdot \mathrm{s}^{-1}$, $60 \%$ relative humidity, and a $12 \mathrm{~h}$ photoperiod. Before freezing, 42-day-old Arabidopsis seedlings were first coldacclimated at $4{ }^{\circ} \mathrm{C}$ for 3 days. After this cold acclimation, the seedlings were subjected to a temperature drop from 4 to $-6{ }^{\circ} \mathrm{C}$ at $2{ }^{\circ} \mathrm{C} / \mathrm{h}$ in the growth chamber, which was maintained at $-6{ }^{\circ} \mathrm{C}$ for $2 \mathrm{~h}$. Then the temperature was raised to $4{ }^{\circ} \mathrm{C}$ at $2{ }^{\circ} \mathrm{C} / \mathrm{h}$. Another group of cold-acclimated Arabidopsis was subjected to $-12{ }^{\circ} \mathrm{C}$ for $10 \mathrm{~h}$ and then kept at $4{ }^{\circ} \mathrm{C}$ in a growth chamber. After $12 \mathrm{~h}$ of further exposure to $4{ }^{\circ} \mathrm{C}$, all Arabidopsis plants were placed in a growth chamber under normal growth conditions for recovery culture for 1 and 3 days. For chilling rice, 21day-old rice seedlings were placed in a growth chamber at 4 or $10{ }^{\circ} \mathrm{C}$ for 6 days, then allowed to recover for 1 and 3 days under normal conditions. Cold-acclimated Arabidopsis and rice grown under normal conditions were used as controls, labelled with the letter " $C$ " in the Tables and Figures. Samples harvested after freezing and chilling treatment are labelled "T". Plants after 1 and 3 days of recovery culture are labelled "R1" and "R3", respectively. 


\section{Lipid extraction and ESI-MS/MS analysis}

Lipid extraction, ESI-MS/MS analysis and quantification were performed as described previously, with minor modifications [19, 25] (Kansas Lipidomics Research Centre, http://www.k-state.edu/lipid/lipidomics). Fully expanded Arabidopsis and rice leaves were harvested at the sampling time and, to inhibit lipolytic activity, were transferred immediately into $3 \mathrm{ml}$ of isopropanol with $0.01 \%$ butylated hydroxytoluene at $75{ }^{\circ} \mathrm{C}$. The tissue was extracted three times with chloroform/methanol (2:1), with $12 \mathrm{~h}$ of agitation each time. The remaining plant tissue was dried overnight at $105{ }^{\circ} \mathrm{C}$ and weighed to give the dry weight of the plants. Lipid samples were analysed on a triple quadrupole MS/MS equipped for ESI. Data were processed as described previously [19, 25]. The lipids in each head-group class were quantified in comparison to two internal standards for the class. Five replicates of each treatment were analysed for each plant.

\section{Statistical procedures}

The Q-test was performed on the total amount of lipid in each head-group class and data from discordant samples were removed $[19,25]$. The data were subjected to one-way analysis of variance (ANOVA) with SPSS 13.0. Statistical significance was tested by Fisher's least significant difference (LSD) method. Hierarchical clustering analysis was performed using Cluster 3.0 and Java TreeView. Principal component analysis was conducted with SPSS 13.0. DBI and ACL were calculated as described previously [14]: DBI $=(\Sigma[N \times$ mol \% lipid $]) / 100$, where $N$ is the number of double bonds in each lipid molecule; $\mathrm{ACL}=(\Sigma[\mathrm{n} \times \mathrm{mol} \%$ lipid $]) / 100$, where $\mathrm{n}$ is the number of acyl carbons in each lipid molecule.

\section{Availability of supporting data}

The datasets supporting the results of this article are included within the article and its additional files.

\section{Additional file}

Additional file 1: Figure S1. Hierarchical average linkage clustering of lipid molecular species relative contents (mol\%). Table S1. Levels of galactolipid species in leaves of Arabidopsis and rice after various low-temperature treatments. Table S2. Component matrix of PCA analysis. Table S3. Lipid ratios of Arabidopsis and rice after various low-temperature treatments. Table S4. Levels of PG molecular species in leaves of Arabidopsis and rice after various low-temperature treatments. Table S5. Levels of PA molecular species in leaves of Arabidopsis and rice after various low-temperature treatments. (DOC $446 \mathrm{~kb}$ )

\section{Abbreviations}

ACL: acyl chain length; DBI: double bond index; DGDG: digalactosyldiacylglycerol; MDGD: monogalactosyldiacylglycerol; PA: phosphatidic acid; PC: phosphatidylcholine; PE: phosphatidylethanolamine;

PG: phosphatidylglycerol; PI: phosphatidylinositol; PS: phosphatidylserine.

\section{Competing interests}

The authors declare that they have no competing interests.

\section{Author's contributions}

WQL conceived the research and designed the experiments. $L X L$ performed the experiments. LXL, WQL and GWZ analysed the data. GWZ wrote the main manuscript text and prepared Figures and Tables. GWZ and WQL revised the manuscript. GWZ and WQL discussed the results and reviewed the manuscript. All authors read and approved the final version of the manuscript.

\section{Acknowledgements}

This work was supported by grants from NSFC 31401313 \& 30670474, West Light Foundation of the Chinese Academy of Sciences (CAS), and the Germplasm Bank of Wild Species. Lipid analysis was performed at the Kansas Lipidomics Research Center.

\section{Author details}

${ }^{1}$ Key Laboratory for Plant Diversity and Biogeography of East Asia, Kunming Institute of Botany, Chinese Academy of Sciences, Kunming, Yunnan 650202, People's Republic of China. ${ }^{2}$ Germplasm Bank of Wild Species, Kunming Institute of Botany, Chinese Academy of Sciences, Kunming 650201, People's Republic of China. ${ }^{3}$ Guiyang Medicinal Botanical Garden, Guiyang 550002, People's Republic of China.

Received: 26 October 2015 Accepted: 15 March 2016

Published online: 22 March 2016

\section{References}

1. Cavender-Bares J. Chilling and freezing stress in live oaks (Quercus section Virentes): intra- and inter-specific variation in PS II sensitivity corresponds to latitude of origin. Photosynth Res. 2007;94:437-53.

2. Xin Z, Browse J. Cold comfort farm: the acclimation of plants to freezing temperatures. Plant Cell Environ. 2000;23:893-902.

3. Shinkawa R, Morishita A, Amikura K, Machida R, Murakawa H, Kuchitsu K, et al. Abscisic acid induced freezing tolerance in chilling-sensitive suspension cultures and seedlings of rice. BMC Res Notes. 2013;6:351.

4. Ploschuk EL, Bado LA, Salinas M, Wassner DF, Windauer LB, Insausti P. Photosynthesis and fluorescence responses of Jatropha curcas to chilling and freezing stress during early vegetative stages. Environ Exp Bot. 2014;102:18-26.

5. Grimaud F, Renaut J, Dumont E, Sergeant K, Lucau-Danila A, Blervacq AS, et al. Exploring chloroplastic changes related to chilling and freezing tolerance during cold acclimation of pea (Pisum sativum L.). J Proteomics. 2013;80:145-59.

6. Chinnusamy V, Zhu J, Zhu JK. Cold stress regulation of gene expression in plants. Trends Plant Sci. 2007;12:444-51.

7. Sung DY, Kaplan F, Lee KJ, Guy CL. Acquired tolerance to temperature extremes. Trends Plant Sci. 2003;8:179-87.

8. Steponkus PL. Role of the plasma membrane in freezing injury and cold acclimation. Annu Rev Plant Physiol. 1984;35:543-84.

9. Hincha DK, Höfner R, Schwab KB, Heber U, Schmitt JM. Membrane rupture is the common cause of damage to chloroplast membranes in leaves injured by freezing or excessive wilting. Plant Physiol. 1987;83:251-3.

10. Krause GH, Grafflage S, Rumich-Bayer S, Somersalo S. Effects of freezing on plant mesophyll cells. Symp Soc Exp Biol. 1988;42:311-27.

11. Nishida I, Murata N. Chilling sensitivity in plants and cyanobacteria: The crucial contribution of membrane lipids. Annu Rev Plant Physiol Plant Mol Biol. 1996:47:541-68.

12. Wang $X$, Li W, Li M, Welti R. Profiling lipid changes in plant response to low temperatures. Physiol Plant. 2006;126:90-6.

13. Li W, Wang R, Li M, Li L, Wang C, Welti R, et al. Differential degradation of extraplastidic and plastidic lipids during freezing and post-freezing recovery in Arabidopsis thaliana. J Biol Chem. 2008:283:461-8.

14. Zheng G, Tian B, Li W. Membrane lipid remodelling of Meconopsis racemosa after its introduction into lowlands from an alpine environment. PLoS One. 2014;9, e106614

15. Zheng G, Tian B, Zhang F, Tao F, Li W. Plant adaptation to frequent alterations between high and low temperatures: remodelling of membrane lipids and maintenance of unsaturation levels. Plant Cell Environ. 2011;34:1431-42. 
16. Uemura M, Joseph RA, Steponkus PL. Cold Acclimation of Arabidopsis thaliana (effect on plasma membrane lipid composition and freeze-induced lesions). Plant Physiol. 1995;109:15-30.

17. Hazei JR, Williams EE. The role of alterations in membrane lipid compositon in enabling physiological adaptation of organisms to their physical environment. Prog Lipid Res. 1990;29:167-227.

18. Moellering ER, Muthan B, Benning C. Freezing tolerance in plants requires lipid remodeling at the outer chloroplast membrane. Science. 2010;330:226-8.

19. Welti R, Li W, Li M, Sang Y, Biesiada H, Zhou HE, et al. Profiling membrane lipids in plant stress responses: Role of phospholipase Da in freezinginduced lipid changes in Arabidopsis. J Bio Chem. 2002;277:31994-2002.

20. Tasseva G, Davy de Virville J, Cantrel C, Moreau F, Zachowski A. Changes in the endoplasmic reticulum lipid properties in response to low temperature in Brassica napus. Plant Physiol Biochem. 2004;42:811-22.

21. Buchanan B, Gruissem W, Jones R. Biochemistry \& molecular biology of plants. Rockville, MD, USA: John Wiley \& Sons; 2002. p. 456-527.

22. Degenkolbe T, Giavalisco P, Zuther E, Seiwert B, Hincha DK, Willmitzer L. Differential remodeling of the lipidome during cold acclimation in natural accessions of Arabidopsis thaliana. Plant J. 2012;72:972-82.

23. Li ZG, Zeng HZ, Ao PX, Gong M. Lipid response to short-term chilling shock and long-term chill hardening in Jatropha curcas L. seedlings. Acta Physiol Plant. 2014;36:2803-14

24. Li W, Li M, Zhang W, Welti R, Wang X. The plasma membrane-bound phospholipase D $\delta$ enhances freezing tolerance in Arabidopsis thaliana. Nature Biotech. 2004;22:427-33.

25. Welti R, Shah J, Li W, Li M, Chen J, Burke JJ, et al. Plant lipidomics: Discerning biological function by profiling plant complex lipids using mass spectrometry. Front Biosci. 2007;12:2494-506.

26. Murata N, Ishizaki-Nishizawa O, Higashi S, Hayashi H, Tasaka Y, Nishida I. Genetically engineered alteration in the chilling sensitivity of plants. Nature. 1992;356:710-3.

27. Sakamoto A, Sulpice R, Hou CX, Kinoshita M, Higashi SI, Kanaseki T, et al. Genetic modification of the fatty acid unsaturation of phosphatidylglycerol in chloroplasts alters the sensitivity of tobacco plants to cold stress. Plant Cell Environ. 2004;27:99-105.

28. Ghanevati M, Jaworski JC. Active-site residues of a plant membrane-bound fatty acid elongase beta-ketoacyl-CoA synthase, FAE1 KCS. Biochim Biophy Acta. 2001;1530:77-85.

29. Janmohammadi M, Zolla L, Rinalducci S. Low temperature tolerance in plants: Changes at the protein level. Phytochem. 2015;117:76-89.

30. Kojima M, Suzuki H, Ohnishi M, Ito S. Efffects of growth tempearture on lipids of Adzuki bean cells. Phytochem. 1998;47:1483-7.

31. Li Q, Zheng Q, Shen WY, Cram D, Fowler DB, Wei YD, et al. Understanding the biochemical basis of temperature-induced lipid pathway adjustments in plants. Plant Cell. 2015;27:86-103.

32. Miquel M, Douglas James J, Dooner H, Browse J. Arabidopsis requires polyunsaturated lipids for low-temperature survival. Proc Natl Acad Sci U S A. 1993;90:6208-12.

33. Heinz E, Roughan PG. Similarities and differences in lipid-metabolism of chloroplasts isolated from 18-3 and 16-3 plants. Plant Physiol. 1983;72:273-9.

34. Heemskerk JWM, Storz T, Schmidt RR, Heinz E. Biosynthesis of digalactosyldiacylglycerol in plastids from $16-3$ and 18-3 plants. Plant Physiol. 1990;93:1286-94

35. Chintalapati S, Kiran MD, Shivaji S. Role of membrane lipid fatty acids in cold adaptation. Cell Mol Biol. 2004;50:631-42.

36. Denich TJ, Beaudette LA, Lee H, Trevors JT. Effect of selected environmental and physico-chemical factors on bacterial cytoplasmic membranes. J Microbiol Meth. 2003;52:149-82.

37. Bakht J, Bano A, Dominy P. The role of abscisic acid and low temperature in chickpea (Cicer arietinum) cold tolerance. II. Effects on plasma membrane structure and function. J Exp Bot. 2006;57:3707-15.

38. Ohlrogge J, Browse J. Lipid biosynthesis. Plant Cell. 1995;7:957-70.

39. Murata N, Tasaka Y. Glycerol-3-phosphate acyltransferase in plants. Bioch Bioph Acta. 1997;1348:10-6.

40. Kim HU, Li Y, Huang AH. Ubiquitous and endoplasmic reticulum-located lysophosphatidyl acyltransferase, LPAT2, is essential for female but not male gametophyte development in Arabidopsis. Plant Cell. 2005;17:1073-89.

41. Mietkiewska E, Brost JM, Giblin EM, Barton DL, Taylor DC. A Teesdalia nudicaulisFAE1 complements the fael mutation in transgenic Arabidopsis thaliana plants and shows a preference for elongating oleic acid to eicosenoic acid. Plant Sci. 2007;173:198-205.
42. Burgos A, Szymanski J, Seiwert B, Degenkolbe T, Hannah MA, Giavalisco P, et al Analysis of short-term changes in the Arabidopsis thaliana glycerolipidome in response to temperature and light. Plant J. 2011;66:656-68.

43. Millar AA, Wrischer M, Kunst L. Accumulation of very-long-chain fatty acids in membrane glycerolipids is associated with dramatic alterations in plant morphology. Plant Cell. 1998;10:1889-902.

44. Li Y, Zheng G, Jia Y, Yu X, Zhang X, Yu B, et al. Acyl chain length of phosphatidylserine is correlated with plant lifespan. PLoS One. 2014;9, e103227.

45. Millar AA, Smith MA, Kunst L. All fatty acids are not equal: discrimination in plant membrane lipids. Trends Plant Sci. 2000;5:95-101.

46. Dörmann P, Benning C. Galactolipids rule in seed plants. Trends Plant Sci. 2002;7:112-8

47. Chen J, Burke JJ, Xin Z, Xu C, Velten J. Characterization of the Arabidopsis thermosensitive mutant atts 02 reveals an important role for galactolipids in thermotolerance. Plant Cell Environ. 2006;29:1437-48.

48. Mishra S, Tyagi A, Singh IV, Sangwan RS. Changes in lipid profile during growth and senescence of Catharanthus roseus leaf. Brazilian J Plant Physiol. 2006;18:447-54

49. Löfke C, Ischebeck T, König S, Freitag S, Heilmann I. Alternative metabolic fates of phosphatidylinositol produced by phosphatidylinositol synthase isoforms in Arabidopsis thaliana. Biochem J. 2008:413:115-24.

50. Stevenson JM, Perera IY, Heilmann I, Persson S, Boss WF. Inositol signaling and plant growth. Trends Plant Sci. 2000;5:252-8.

51. Drøbak BK, Dewey RE, Boss WF. Phosphoinositide kinases and the synthesis of polyphosphoinositides in higher plant cells. In: Kwang WJ, editor. International review of cytology. London: Academic; 1999. p. 95-130.

52. Liu X, Zhai S, Zhao Y, Sun B, Liu C, Yang A, et al. Overexpression of the phosphatidylinositol synthase gene (ZmPIS) conferring drought stress tolerance by altering membrane lipid composition and increasing ABA synthesis in maize. Plant Cell Environ. 2013;36:1037-55.

53. Jia Y, Tao F, Li W. Lipid profiling demonstrates that suppressing Arabidopsis phospholipase Ddelta retards ABA-promoted leaf senescence by attenuating lipid degradation. PLoS One. 2013;8, e65687.

54. Wang $X$. Regulatory functions of phospholipase D and phosphatidic acid in plant growth, development, and stress responses. Plant Physiol. 2005;139:566-73.

55. Zhang Y, Zhu H, Zhang Q, Li M, Yan M, Wang R, et al. Phospholipase Da1 and phosphatidic acid regulate NADPH oxidase activity and production of reactive oxygen species in ABA-mediated stomatal cosure in Arabidopsis. Plant Cell. 2009;21:2357-77.

56. Leeuwen W, Okresz L, Bogre L, Munnik T. Learning the lipid language of plant signalling. Trends Plant Sci. 2004;9:378-84.

\section{Submit your next manuscript to BioMed Central and we will help you at every step:}

- We accept pre-submission inquiries

- Our selector tool helps you to find the most relevant journal

- We provide round the clock customer support

- Convenient online submission

- Thorough peer review

- Inclusion in PubMed and all major indexing services

- Maximum visibility for your research

Submit your manuscript at www.biomedcentral.com/submit 